PPPL-2828

PPPL-2828

UC-427

COMPARISON OF ATF AND TJ-II STELLARATOR EQUILIBRIA AS COMPUTED BY THE 3-D VMEC AND PIES CODES

BY

J.L. JOHNSON, D.A. MONTICELLO, ET. AL.

January 1992

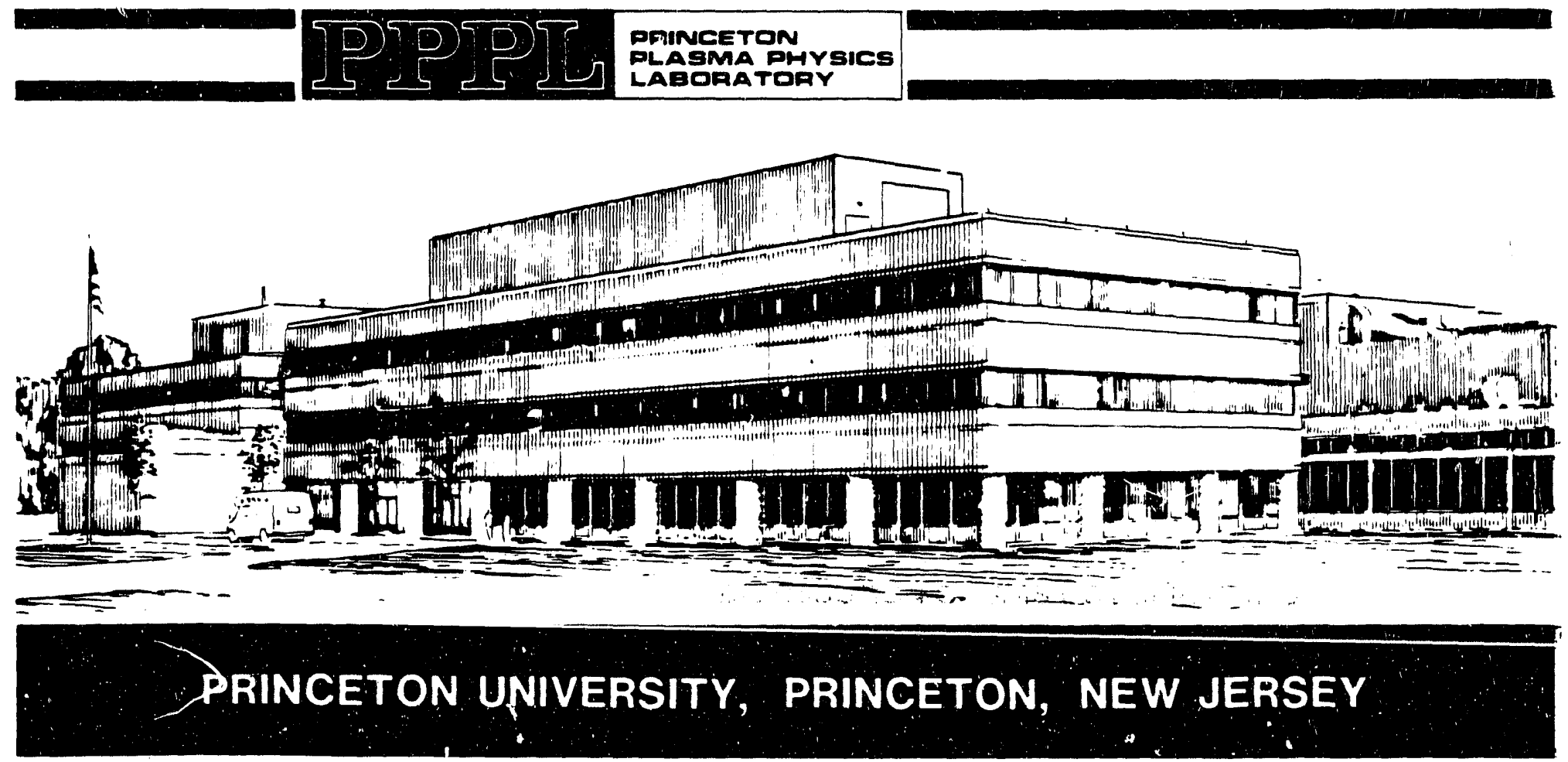




\title{
COMPARISON OF ATF AND TJ-II STELLARATOR EQUILIBRIA AS COMPUTED BY THE 3-D VMEC and PIES CODES
}

\author{
J. L. Johnson, D. A. Monticello, and A. H. Reiman \\ Plasma Physics Laboratory, Princeton University \\ PPPL- -2828 \\ A. Salas and A. L. Fraguas \\ DE92 008654 \\ Asociacion EURATOM-CIEMAT para Fusion, Madrid
}

S. P. $\mathrm{H}_{14}$ shman

Oak Ridge National Laboratory

\begin{abstract}
A comparison is made of results from the PIES code, which determines the equilibrium properties of three-dimensional toroidal configurations by direct integration along the magnetic field lines, with those from the VMEC code, which uses an energy minimization in a flux representation to determine the equilibrium configuration, for two devices: the ATF stellarator at Oak Ridge and the TJ-II heliac which is being built in Madrid. The results obtained from the two codes are in good agreement, providing additional validation for the codes.
\end{abstract}




\section{INTRODUCTION}

The PIES code [1] is a magnetohydrodynamic code that determines three-rl mensional toroidal equilibrium configurations by direct integration along the field lines. It can thus study systems with magnetic islands and multiple magnetic axes. This code has, until now. been used mainly for study of problems associated with tokamak configurations: investigations of the nonlinear saturation of tearing modes, the behavior of magnetic surfaces in the presence of error fields, etc.

The VMEC code [2], on the other hand, determines the equilibrium properties of such configurations by minimizing the energy. It is based on an 'inverse solver' technique in which a set of well behaved nested magnetic surfaces must be postulated to exist. It has been carefully optimized to give an accurate description of the flux surfaces with a minimum amount of computation effort and a minimum number of poloidal harmonics (e.g., as comparerl with a polar coordinate representation). Thus, it is less suited for study of configurations with magnetic islands. Nevertheless, it has been the principal tool for the determination of equilibrium configurations for the design of stellarators.

It has long been recognized that comparisons of the calculations of the equilibrium properties of stellarators such as ATF, LHD, W7-AS, TJ-II, etc., by these two different approaches would be useful. Such calculations would provide additional validation for both codes and thus make additional tools available for the study of complex config irations. We have begun such a study for two stellarators: the ATF torsatron at Oak Ridge and the TJ-II heliac which is being built in Madrid. Detailed results from calculations for racuum and low- $\beta$ equilibria with good magnetic surfaces in both systems show excellent agreement.

In this work we specify the shape of an outer boundary of the plasma by giving the number of field periods.$V$ and the parameters $R_{m, n}$ and $Z_{m, n}$, such that

$$
\begin{aligned}
& R(\theta, \phi)=\sum R_{m, n} \cos (m \theta-n N \phi), \\
& Z(\theta, \phi)=\sum Z_{m, n} \sin (m \theta-n N \phi) .
\end{aligned}
$$

We choose our pressure distribution such that

$$
p(s)=p_{0}(1-s)^{2},
$$

where the parameter $s$ is given by

$$
s \equiv \frac{\psi-\psi_{\text {axis }}}{\psi_{\text {edge }}-\psi_{\text {axis }}}
$$

with $\psi$ the toroidal flux inside the surface, and keep

$$
\int J_{\phi} d S=0 .
$$

Studies of an ATF configuration with $\langle\beta\rangle=0 \%$ and one with $\langle 3\rangle=1.1 \%$ are given in Section II, and similar studies for a TJ-II system with $\langle 3\rangle=0$ 名 and one with $<\beta\rangle=0.34 \%$ are given in Section III. Here $\beta$ is the ratio of the pressure averaged over the plasma cross section, normalized to $B^{2} / 2 \mu_{0}$ at the magnetic axis. Some observations about the results and future work follow in Section IV. 


\section{The ATF Configuration}

The ATF torsatron [3] is the largest stellarator in the United States and has been operating for several years at the Oak Ridge National Laboratory. It has been used for comparison studies of various codes so that it provides a useful configuration for study. We consider a model for it with a magnetic field $B=2 \mathrm{~T}$, helicity $\ell=2, N=12$ field periods. major radius $R_{\text {Major }}=2.1 \mathrm{~m}$, and a plasma boundary given in Table 1 .

We carried through a comparison of the vacuum field $\langle\beta\rangle=0$ configuration using several different mesh sizes for each code. We used $k=15,30$, and 45 surfaces with both $m=0, \cdots, 4$ polcidal modes, and $n=-2, \cdots, 2$ toroidal modes, and $m=0, \cdots, 10, n=-3$, $\cdots, 3$ with the PIES code, and $k=15,30$, and 45 surfaces with $m=0, \cdots, 5, n=-6, \cdots, 6$ with the VMEC code. The shapes of the magnetic surfaces of the configuration in this case, as computed by the PIES code, are given in Fig. 1.

The $\langle\beta\rangle=1.1 \%$ work used the same boundary shape as in the vacuum-field case and had the pressure distribution of Eq. (2) with $\beta(0)=0.0325$. In this case, the PIES code was exercised with $k=15,30$, and 45 surfaces with both $m=0, \cdots, 4, n=-2, \cdots, 2$, and $m=0, \cdots, 10, n=-3, \cdots, 3$. The VMEC code was run with $k=15,30,45$ and 60 surfaces with both $m=0, \cdots, 5, n=-6, \cdots, 6$ and $m=0, \cdots, 9, n=-4, \cdots, 4$. The shapes of the magnetic surfaces, as computed by the PIES code, are given in Fig. 2.

A comparison of the rotational transform, $t(s)$, as a function of the surface label is given in Fig. 3. The well known phenomena of an increase in the value of $t(0)$ with 3 due to an outward shift of the magnetic axis is observed. The extrapolation to infinite mesh of the rotational transform at the magnetic axis is shown in Fig. 4. This result should be considered good since $\boldsymbol{t}$ is not a primary variable in the VMEC code and its determination is difficult. The extrapolation of the location of the magnetic axis with mesh size is given in Fig. 5 . Again, the results agree well. The average magnetic well is given by $[d V(s) / d s] /[d u(s) / d s]$. where $V(s)$ and $\psi(s)$ are the volume and toroidal flux inside the surface $s$, respectively: This function is given in Fig. 6. The excellent agreement is indicative of the quality of the results from the two codes. The vacuum-field ATF has a small well in the inner part of the discharge. The effect of the plasma pressure is to strongly deepen this well and extend the region that it occupies. The function $d p / d V$, with $p(s)$ the pressure and $V(s)$ the volume inside a surface, is a good measure of the shapes of the magnetic surfaces. It is shown in Fig. 7 and again demonstrates the excellent agreement between the two codes.

The results with the finest grids and the largest number of Fourier terms were shown in these figures. There were small differences between the results with different numbers of Fourier terms, but the configurations were more sensitive to the number $k$ of radial mesh points. Near the magnetic axis, a larger number must be used with the VIEC code than with PIES to get into the asymptotic domain where things scale as $1 / k^{2}$. The PIES corle worked well with $m \leq 12$, such that $m_{t}-n N \neq 0$ anywhere in the plasma. Islands can arise at the rational surfaces where this condition is violated. We had trouble with convergence with the PIES code for values of $m$ between 13 and 19 because we did not have enough Fourier modes to properly describe the islands that can arise. Increasing $m$ to values between 20 and 24 (above which singularities with $n=2$ could arise) solved this problem. as can be seen in Fig. 8 where we compare the rotational transform as calculated with $k=30, m=21$. 
$n=3$ and $k=30, m=10, n=3$. A very thin set of islands is developing near the plasma surface for the $m=21$ case. We should use a larger value of $k$ to properly resolve them.

It is difficult to make a fair comparison of the timing of the two codes because fewer radial surfaces are usually needed by the PIES code to obtain a given accuracy than with the VMEC code. To get a rough indication of the time required by the two codes, we ask what would be needed to determine the magnetic axis to within $1 \%$ of the minor radius. In this case, the $k=30 \mathrm{VMEC}$ run, using 1.5 minutes, would be adequate. One could get this accuracy with the PIES code using $k=10$ and 8 iterations, taking 8.4 minutes. This time advantages of the VMEC code should be expected as much effort has been put into its optimization. No work has yet been done to make the PIES code efficient and a significant improvement should be possible. At present then, the VMEC code is clearly preferable for scoping studies, but the PIES code contains more physics and can treat configurations with magnetic islands and ergodic regions.

\section{The TJ-II Configuration}

The TJ-II heliac [4] is being constructed in Spain. It will be used for studies of modes in a configuration with a strongly varying magnetic axis. We model it with a field $B=1 \mathrm{~T}$. major helicity $\ell=1, V=4$ field periods, major radius $R_{\text {Major }}=1.5 \mathrm{~m}$, and the boundary of Table 2.

We carried through a comparison of the vacuum field $\langle\beta\rangle=0$ configuration using several different mesh sizes for each code. We used $k=15,30$, and 45 surfaces with $m=0$. $\cdots, 5$ poloidal modes and $n=-12, \cdots, 12$ toroidal modes with the PIES code, and $k=15$. 30,45 , and 60 surfaces with $m=0, \cdots, 6, n=-12, \cdots, 12$ with the V.MEC code. The shapes of the magnetic surfaces in this case, as computed by the PIES code, are given in Fig. 9.

The $\langle\beta\rangle=0.34 \%$ work used the same boundary shape as in the vacuum-field case and had the pressure distribution of $\mathrm{Eq}$. (2) with $\beta(0)=0.00992$. In this case. the PIES code was exercised with $k=15$ and 30 surfaces with $m=0, \cdots, 5, n=-12, \cdots, 12$. The VMEC code was run with $l:=30,45$, and 60 surfaces with $m=0, \cdots, 6, n=-12, \cdots, 12$. The shapes of the magnetic surfaces are given in Fig. 10.

A comparison of the rotational transform, $t(s)$, as a function of the surface label is given in Fig. 11. The differences betiveen the predictions of the codes improves as the meshes are refined. Since the transform is nearly constant for this configuration, the differences appear to be exaggerated. The extrapolation to infinite mesh of the position of the magnetic axis in Fig. 12 provides confirmation of agreement between the codes. The most striking feature of this device is that the rotational transform near the axis is decreased as 3 is increased. This occurs even though there is an improvement in the magnetic well, as can be seen in Fig. 1:3. where the shape of $V^{\prime \prime}(\psi)$ is favorable and shows good agreement. 


\section{CONCLUSIONS}

The good agreement that has been found for the ATF and TJ-II stellarators with sufficient pressure to modify the equilibria significantly provides a strong validation of both codes. It will be useful to extend these studies to configurations with higher $\beta$ where magnetic islands should be expected.

\section{ACKNOWLEGEMENTS}

This work was supported by the U.S. Department of Energy under Contract \# DEACO2-76-CHO-3073 with Princeton University and Contract DE-AC05-840R21400 with Oak Ridge National Laboratory which is operated by Martin Marietta Energy Systems, Inc. Part of this work was done while A. Salas was visiting the Princeton Plasma Physics Laborators: 


\section{REFERENCES}

[1] A. Reiman and H. Greenside, Comput. Phys. Commun. 43, 157 (1986).

[2] S. P. Hirshman, W. I. van Rij, and P. Merkel, Comput. Phys. Commun. 43, 143 (1986).

[3] J. F. Lyons, G. L. Bell, J. D. Bell, R. D. Benson, T. S. Bigelow, K. K. Chipley, R. J. Colchin, M. J. Cole, E. C. Crume, J. L. Dunlap, A. C. England, J. C. Glowientia, R. H. Goulding, J. H. Harris, D. L. Hills, S. Hiroe, K, D. Horton, H. C. Howe, R. C. Isler, T. C. Jernigan, R. L. Johnson, R. A. Langley, M. M. Menon, P. K. Mioduszewski. R. N. Morris, M. Murakami, G. H. Nielson, B. E. Nelson, D. A. Rassmussen, J. A. Rome, M. J. Saltmarsh, P. B. Thompson, M. R. Wade, J. A. White, T. L. White, J. C. Whitson, J. B. Wilgen, and W. R. Wing, Fusion Technology 17, 33 (1990).

[4] C. Alejaldre, J. J. Alonso-Gozalo, J. Botija-Perez, F. Castejón-Magaña, J. R. CeperoDiaz, J. Guasp-Perez, A. Lopez-Fraguas, L. Garcia, V. I. Krivenski, R. Martin. A. P. Navarro, A. Perea, A. Rodriguez-Yunta, M. Sorolla-Ayza, and A. Varias, Fusion Technology 17, 131 (1990). 
Table 1. ATF Boundary Specifications

\begin{tabular}{ccccc} 
& & \multicolumn{3}{c}{$R_{m, n}(\mathrm{~cm})$} \\
$n \backslash m$ & 0 & 1 & 2 & 3 \\
-2 & 0.0 & 0.0 & 0.0 & 0.0 \\
-1 & 0.0 & 0.19 & 0.28 & 0.0 \\
0 & 206.28 & 27.05 & -0.14 & 0.20 \\
1 & & -7.07 & -1.08 & 0.10 \\
2 & & 0.0 & 0.14 & 0.0 \\
& & & & \\
& & & $Z_{m, n}(\mathrm{~cm})$ & \\
$n \backslash m$ & 0 & 1 & 2 & 3 \\
-2 & 0.0 & 0.0 & 0.0 & 0.0 \\
-1 & 0.0 & 0.57 & 0.32 & 0.0 \\
0 & 0.0 & 30.74 & -0.19 & -0.14 \\
1 & & 7.82 & 1.12 & -0.07 \\
2 & & 0.0 & -0.15 & 0.0
\end{tabular}


TABLE 2 TJ-II Boundary Specifications

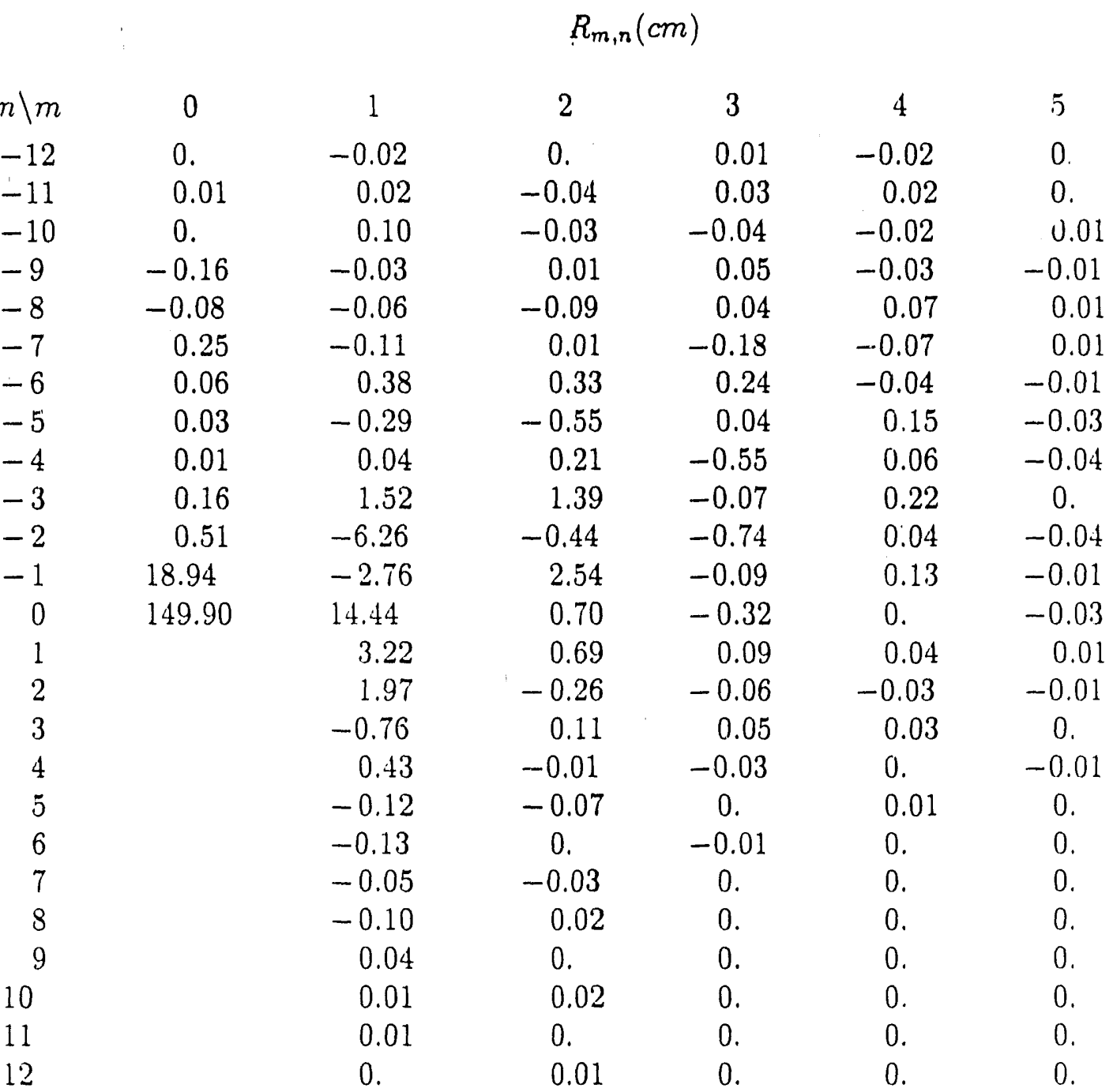


TJ-II Boundary Specifications (continued)

\begin{tabular}{ccccccc} 
& \multicolumn{5}{c}{$Z_{m, n}(\mathrm{~cm})$} \\
$n \backslash m$ & 0 & 1 & 2 & 3 & 4 & \\
-12 & 0. & 0.01 & 0.01 & 0. & 0.01 & 0. \\
-11 & -0.02 & 0. & 0.04 & -0.03 & -0.01 & 0. \\
-10 & -0.01 & -0.15 & 0.06 & 0.05 & 0. & 0. \\
-9 & 0.11 & -0.15 & -0.15 & 0.03 & 0.03 & 0.01 \\
-8 & 0.05 & 0.08 & -0.11 & -0.11 & -0.05 & -0.01 \\
-7 & 0.39 & -0.11 & 0.28 & 0.18 & 0.02 & 0.01 \\
-6 & 0.09 & 0.11 & -0.32 & -0.09 & 0.07 & 0.02 \\
-5 & 0.03 & 0.49 & 0.15 & -0.35 & -0.16 & -0.01 \\
-4 & 0. & -1.17 & 1.06 & 0.75 & -0.11 & 0.03 \\
-3 & -0.16 & 1.04 & -2.67 & 0.48 & -0.05 & 0.03 \\
-2 & -0.54 & 3.62 & -1.60 & -0.24 & 0.04 & 0.02 \\
-1 & -18.54 & -2.40 & 2.79 & -0.32 & 0.02 & -0.01 \\
0 & 0. & 16.43 & 1.40 & -0.34 & 0. & 0. \\
1 & & 2.65 & 0.74 & -0.03 & 0.02 & 0. \\
2 & & 2.48 & -0.26 & -0.10 & 0.01 & 0. \\
3 & & -0.93 & 0.13 & 0.11 & -0.01 & 0. \\
4 & & 0.47 & -0.05 & 0. & -0.01 & 0. \\
5 & & -0.18 & 0.03 & 0.04 & -0.01 & 0. \\
6 & & -0.03 & -0.05 & 0. & 0. & 0. \\
7 & & -0.08 & -0.02 & -0.01 & 0. & 0. \\
8 & & -0.13 & 0.01 & -0.01 & 0. & 0. \\
9 & & 0.02 & 0.02 & -0.01 & 0. & 0. \\
10 & & 0.02 & -0.02 & 0. & 0. & 0. \\
11 & & 0.01 & 0.01 & 0. & 0. & 0. \\
12 & & 0. & 0.01 & 0. & 0. & 0.
\end{tabular}




\section{FIGURE CAPTIONS}

Fig. 1 The vacuum field ATF equilibrium configuration at three toroidal angles, $\phi=0, \pi / 4 N$, and $\pi / 2 N$, as computed by the PIES code.

Fig. 2 The $\langle\beta\rangle=1 \%$ ATF equilibrium configuration at three toroidal angles, $\phi=0, \pi / 4 N$, and $\pi / 2 N$, as computed by the PIES code.

Fig. 3 Rotational transform, $t(s)$, as a function of the flux label $s$ for the ATF configuration. In the lower curves, which correspond to $\langle\beta\rangle=0 \%$, the t's are from the $k=45$, $m=10, n=3$ PIES code calculation; the $\times$ 's are from the $k=45, m=5, n=6$ VMEC code. In the upper curves with $\langle\beta\rangle=1 \%$, the + 's are from the $k=45, m=10$, $n=3$ PIES code calculation; the $\times$ 's are from the $k=60, m=5, n=6$ VMEC code.

Fig. 4 Rotational transform at the magnetic axis, $t(0)$, for the ATF configuration as a function of mesh size. The +'s are from the $m=10, n=3$ PIES code and the $x$ 's are from the $m=5, n=6 \mathrm{VMEC}$ code in the $\langle\beta\rangle=0 \%$ lower curves. The $\times$ 's are from the $m=10, n=3$ PIES code and the ' $t$ ' are from the $m=9, n=4$ VMEC code in the $\langle\beta\rangle=1 \%$ upper curves.

Fig. 5 The location of the magnetic axis at $\phi=0$ for the ATF configuration. The symbols are the same as in Fig. 4.

Fig. 6 The function $V^{\prime}(\psi)$ as a function of $s$ for the vacuum field ATF configuration, with the symbols the same as in Fig. 3.

Fig. 7 The function $d p(s) / d V(s)$ as a function of $s$ for the $\langle\beta\rangle=1 \%$ ATF configuration, with the symbols the same as in Fig. 3.

Fig. 8 Comparison of the rotational transform, $t(s)$, in the $\langle\beta\rangle=1 \%$ ATF corifiguration as computed with $m=10$ ( $\times$ 's) and $m=21$ (t's).

Fig. 9 The vacuum field TJ-II equilibrium configuration at three toroidal angles, $\phi=0, \pi / 2 N$, and $\pi / N$, as computed by the PIES code.

Fig. 10 The $<\beta>=0.3 \%$ TJ-II equilibrium configuration at three toroidal angles, $\phi=0$, $\pi / 2 N$, and $\pi / N$, as computed by the PIES code.

Fig. 11 Rotational transform, $t(s)$, as a function of the flux label $s$ for the TJ-II configuration. In the upper curves, which correspond to $\langle\beta\rangle=0 \%$, the t's are from the $k=15$, $m=5, n=12$ PIES code calculation; the $\times$ 's are from the $k=45, m=5, n=12$ VMEC code. In the lower curves with $\langle\beta\rangle=1 \%$, the +'s are from the $k=30, m=5$, $n=12$ PIES code calculation; the $\times$ 's are from the $k=60, m=6, n=12$ VMEC code.

Fig. 12 The location of the magnetic axis at $\phi=0$ for the TJ-II configuration. In both the lower curves, which corresponds to $\langle\beta\rangle=0$, and the upper curves for $\langle\beta\rangle=0.3 \%$, the + 's are from PIES and the $\times$ 's are from VMEC.

Fig. 13 The function $V^{\prime \prime}(\psi)$ as a function of $s$ for TJ-II, with the symbols the same as in Fig. 11. 


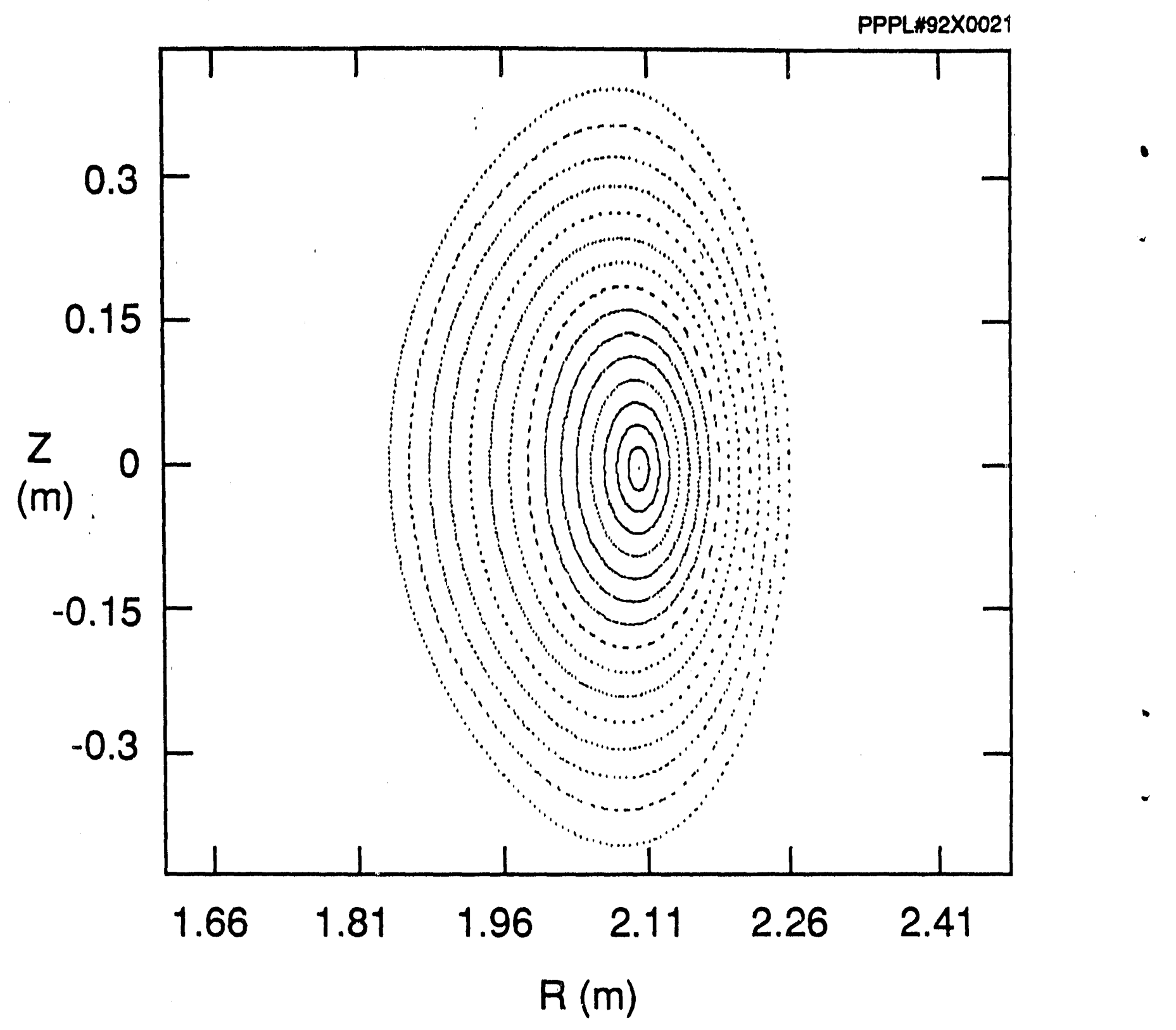

Fig. 1A 


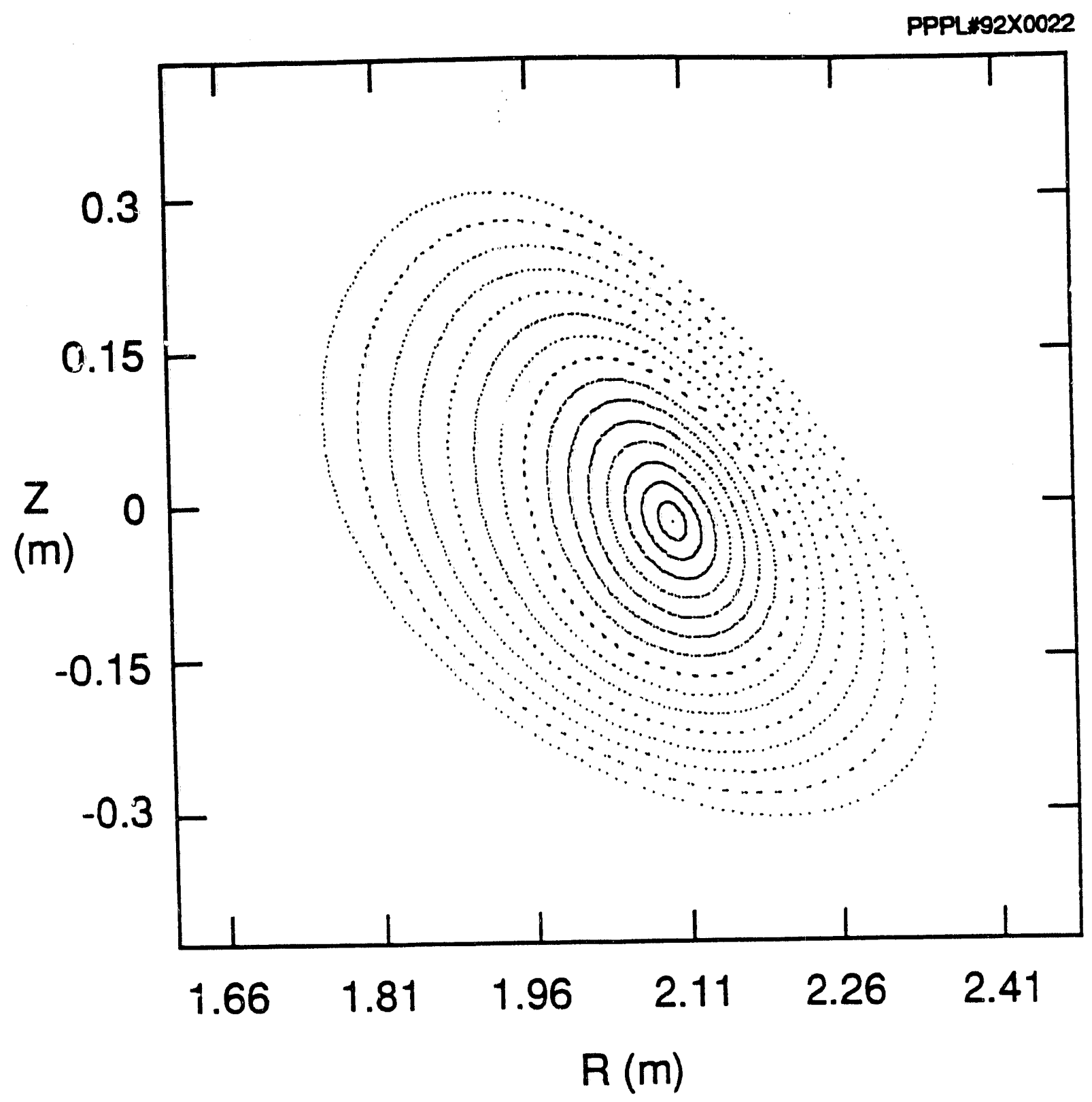

Fig. 1B 


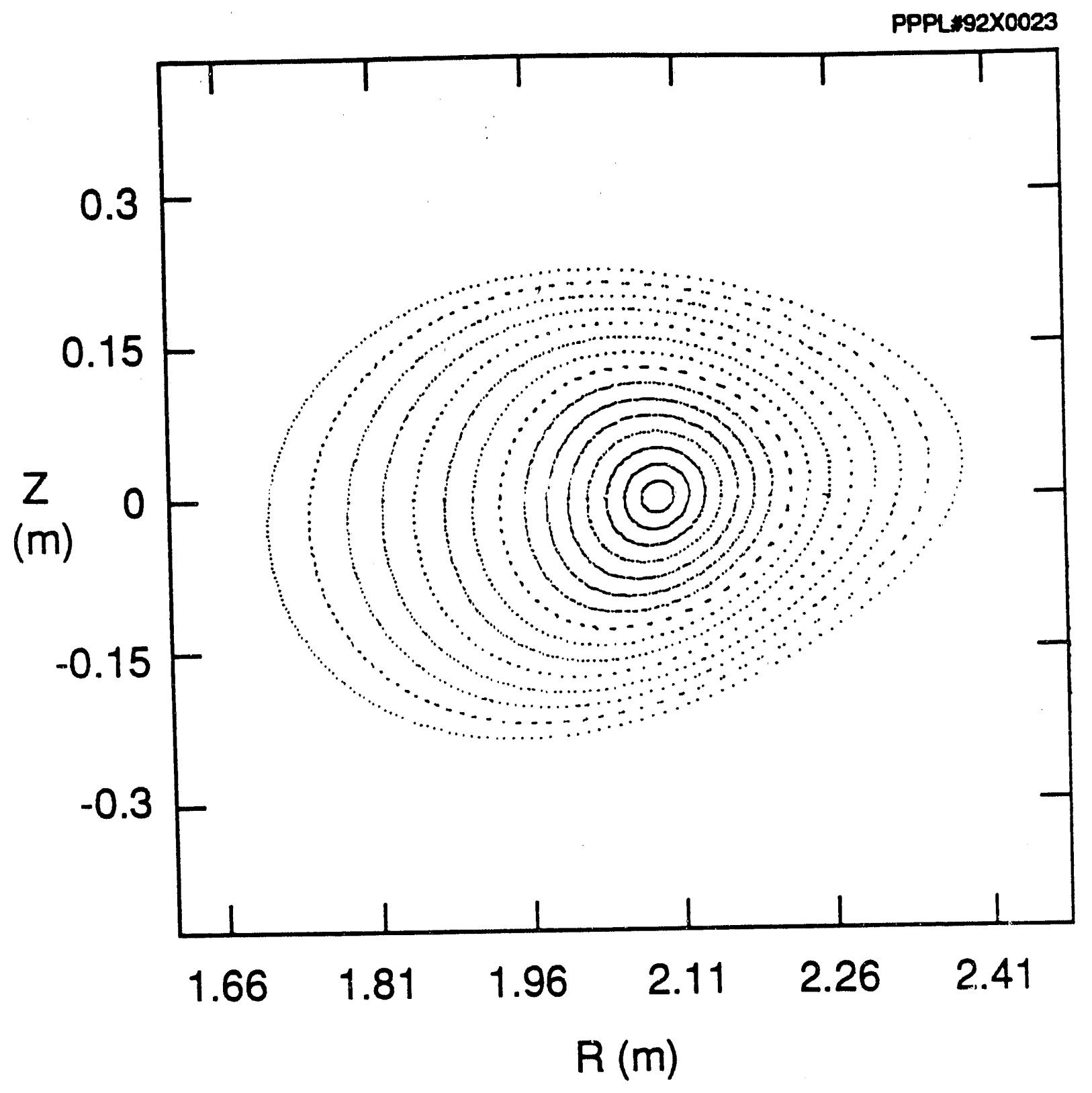

Fig. 1C 


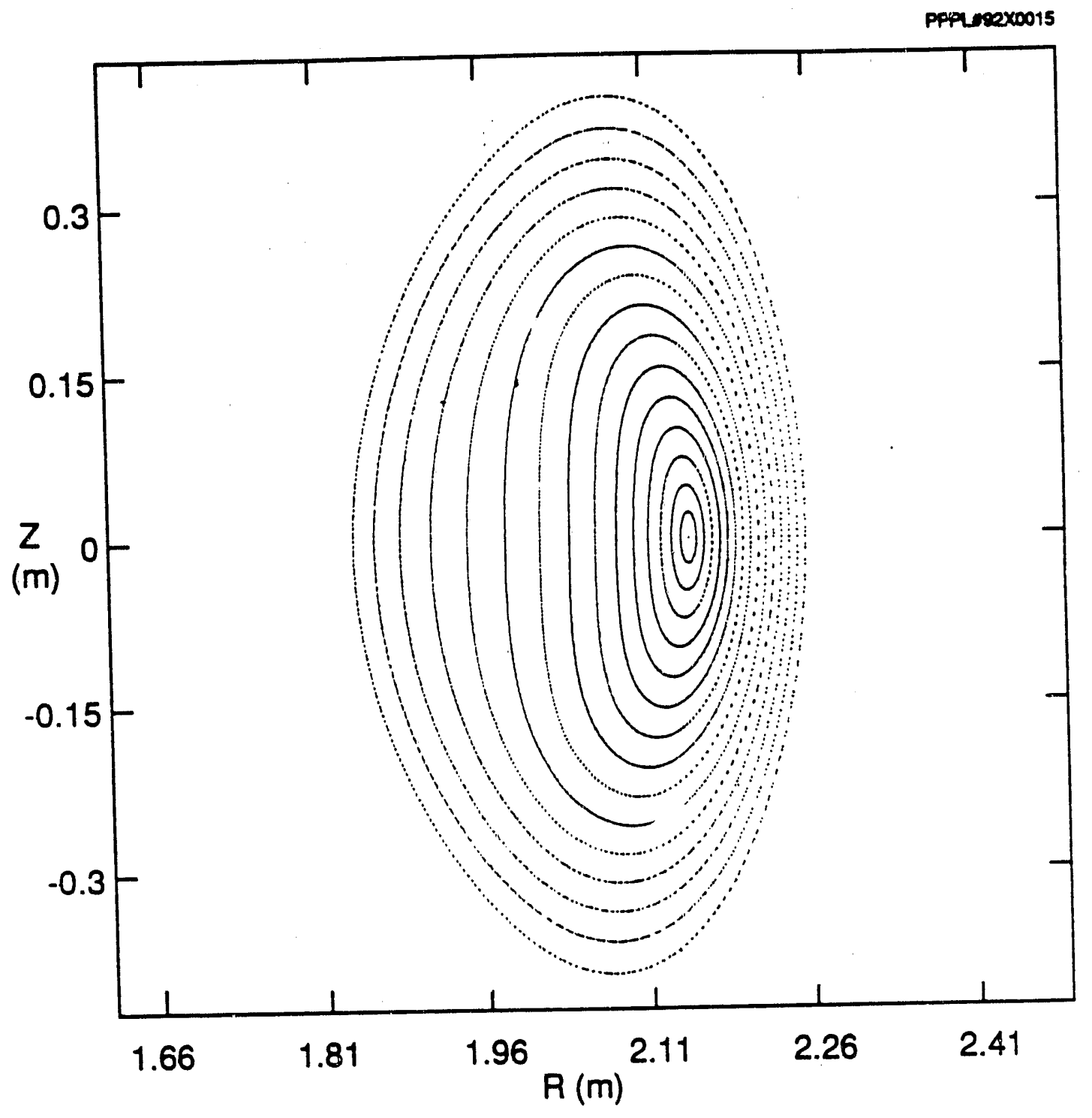

Fig. 2A 


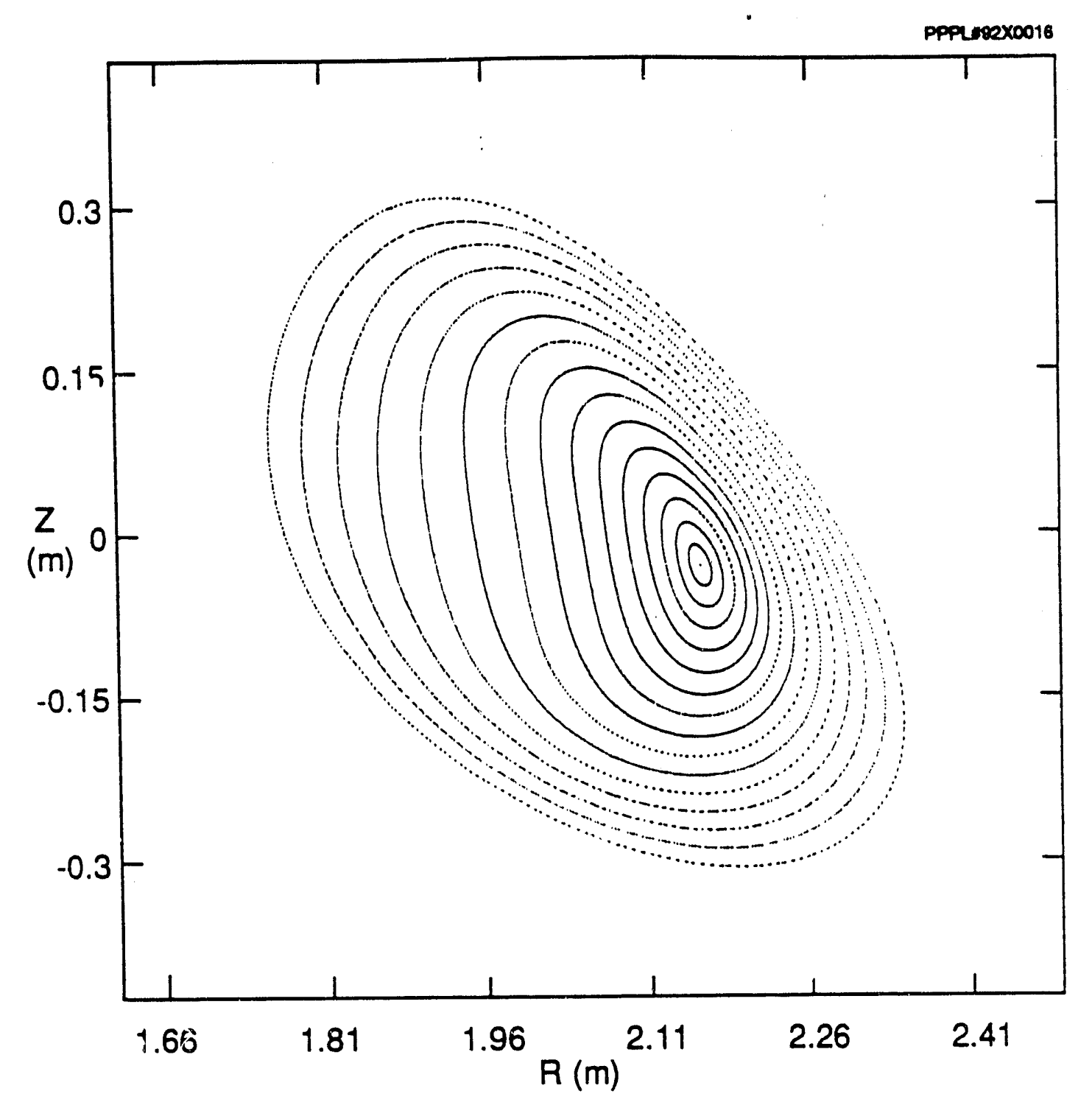

Fig. 2B 


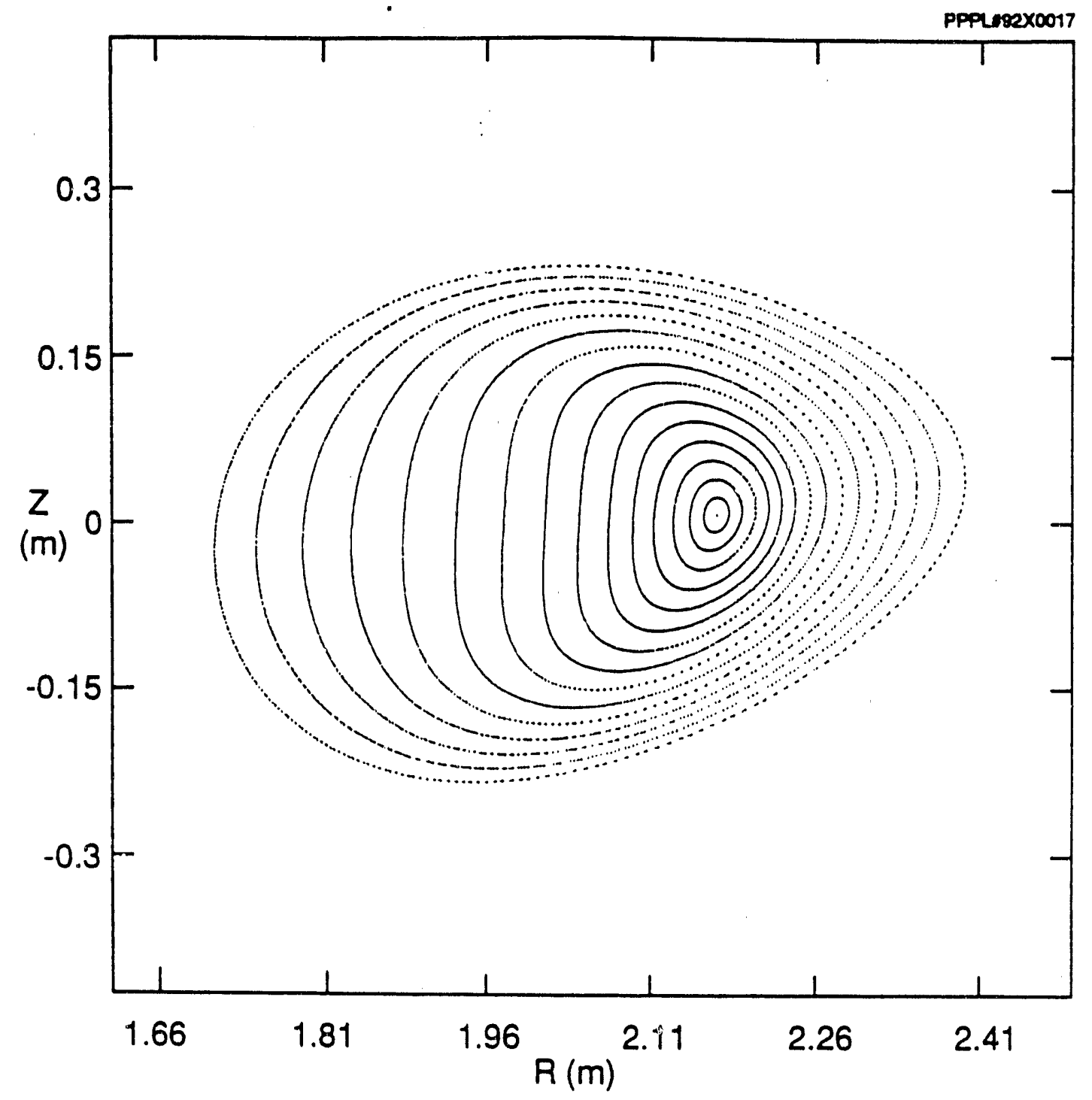

Fig. $2 C$

Fig. 2C

15 


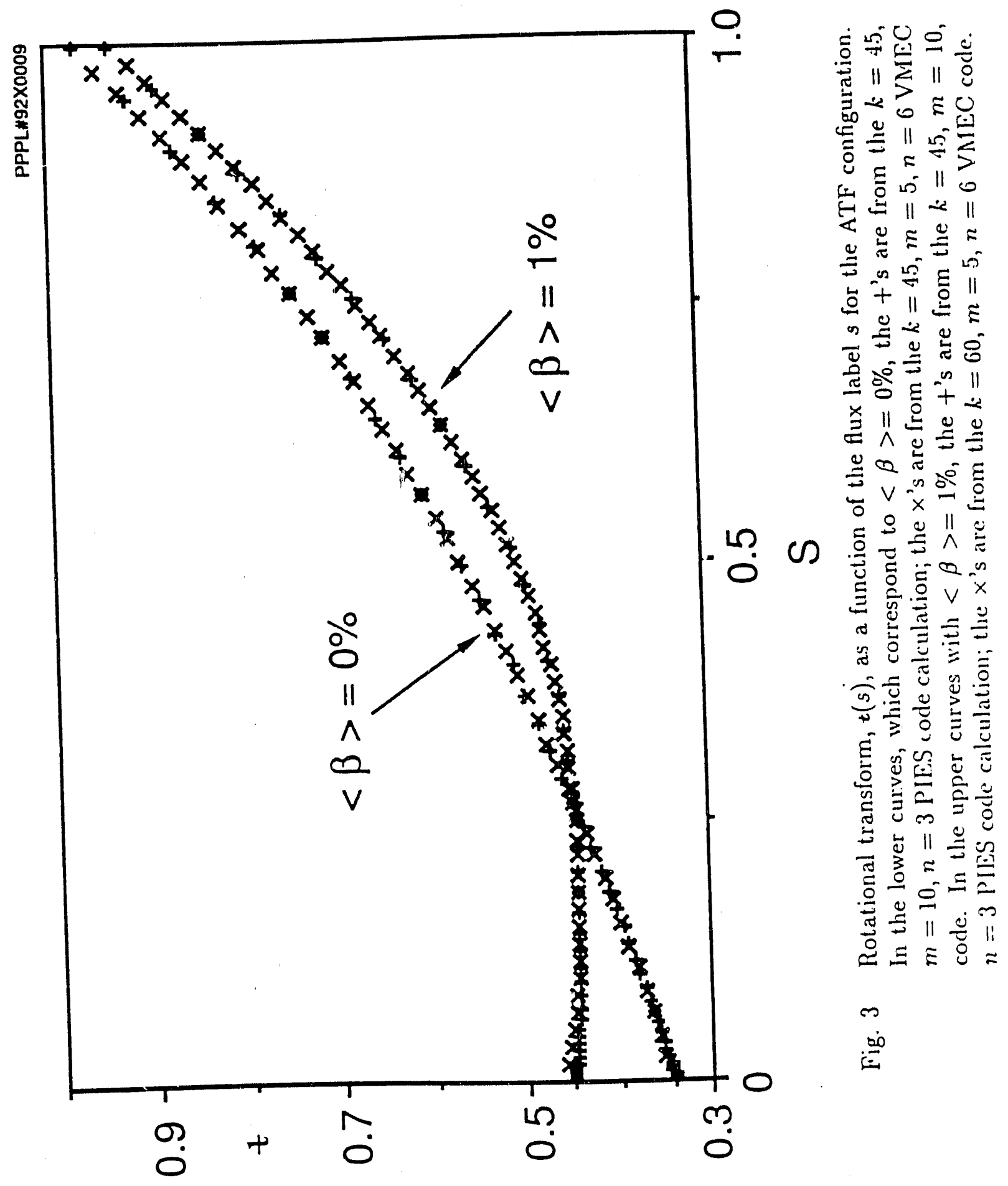

16 


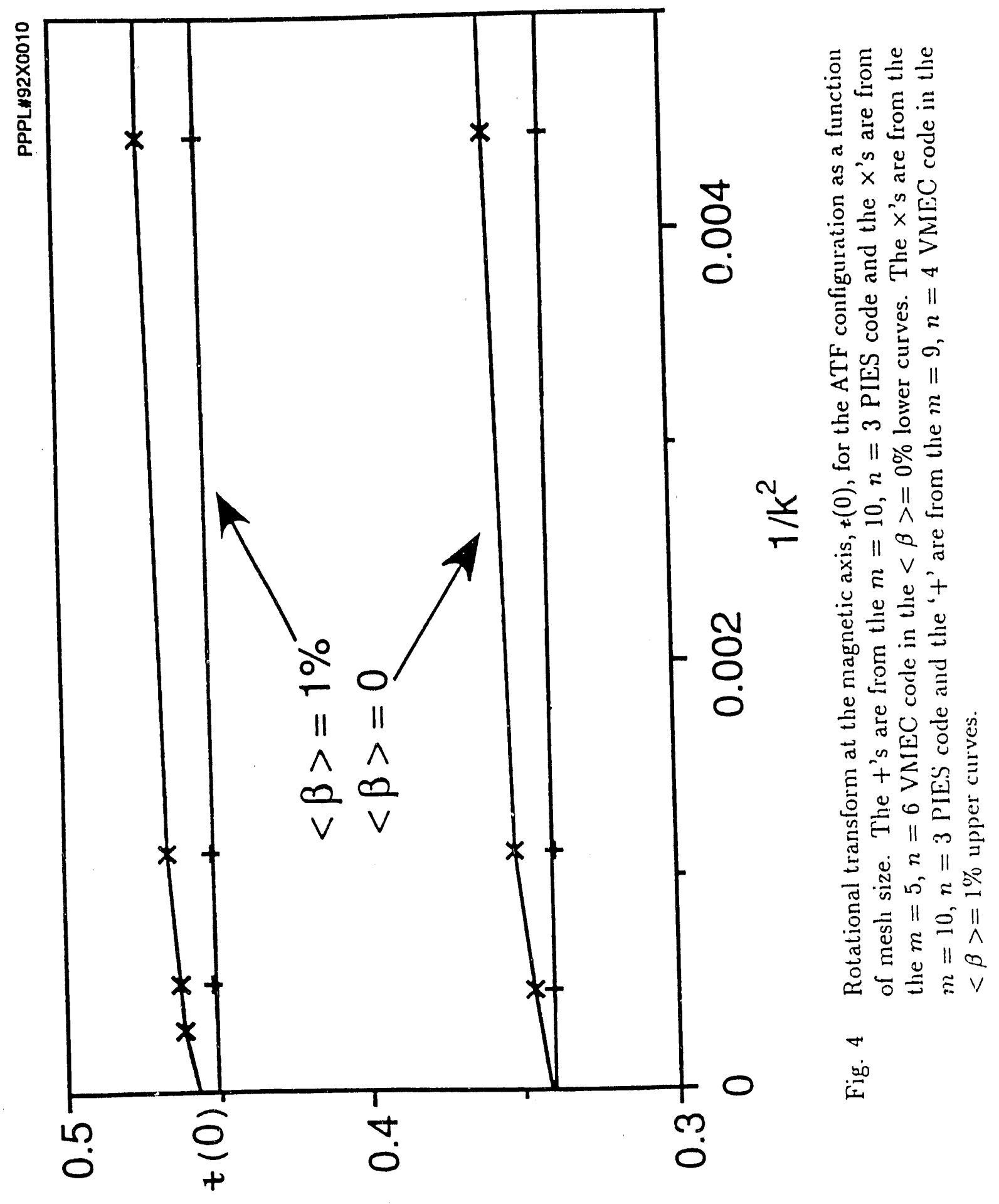




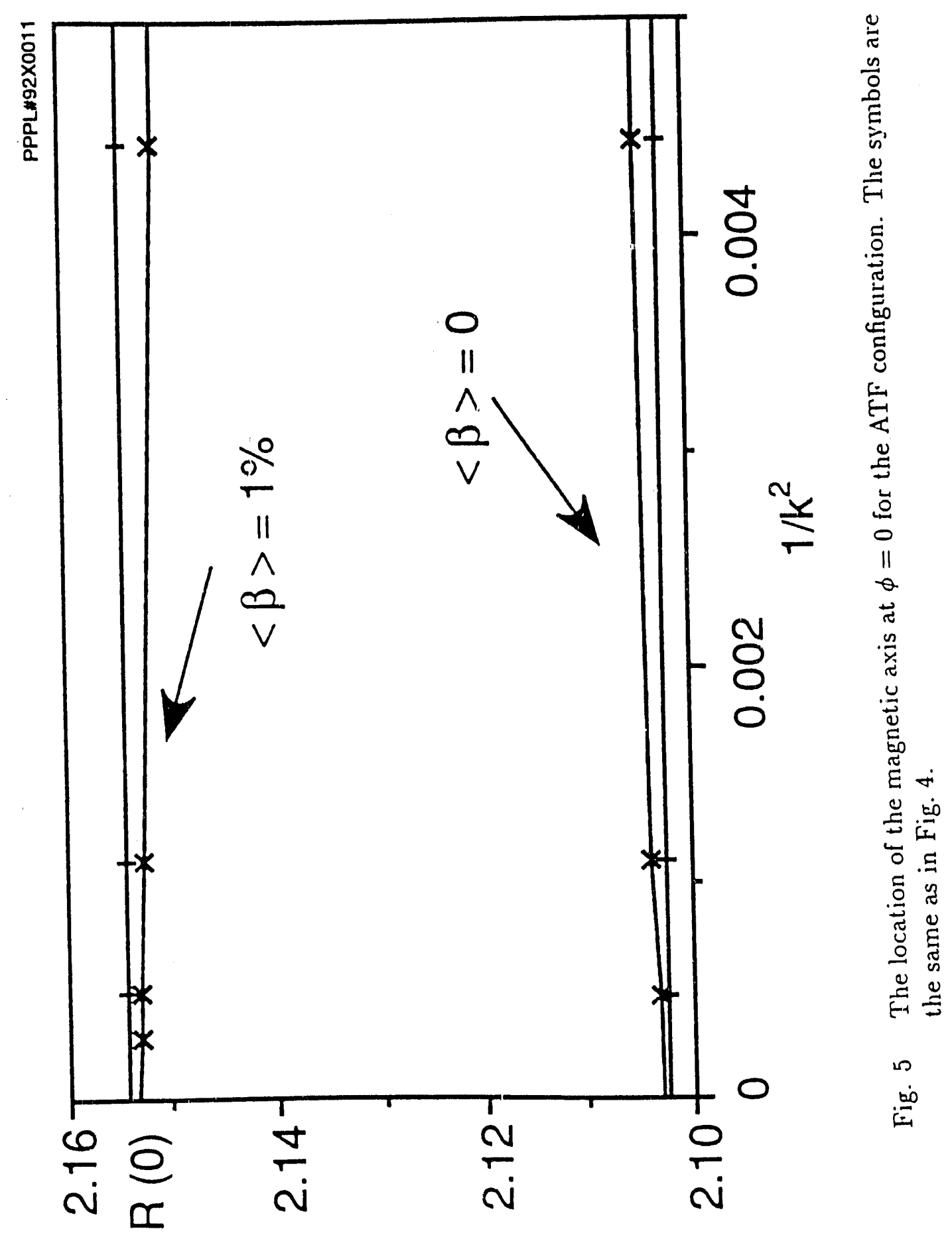




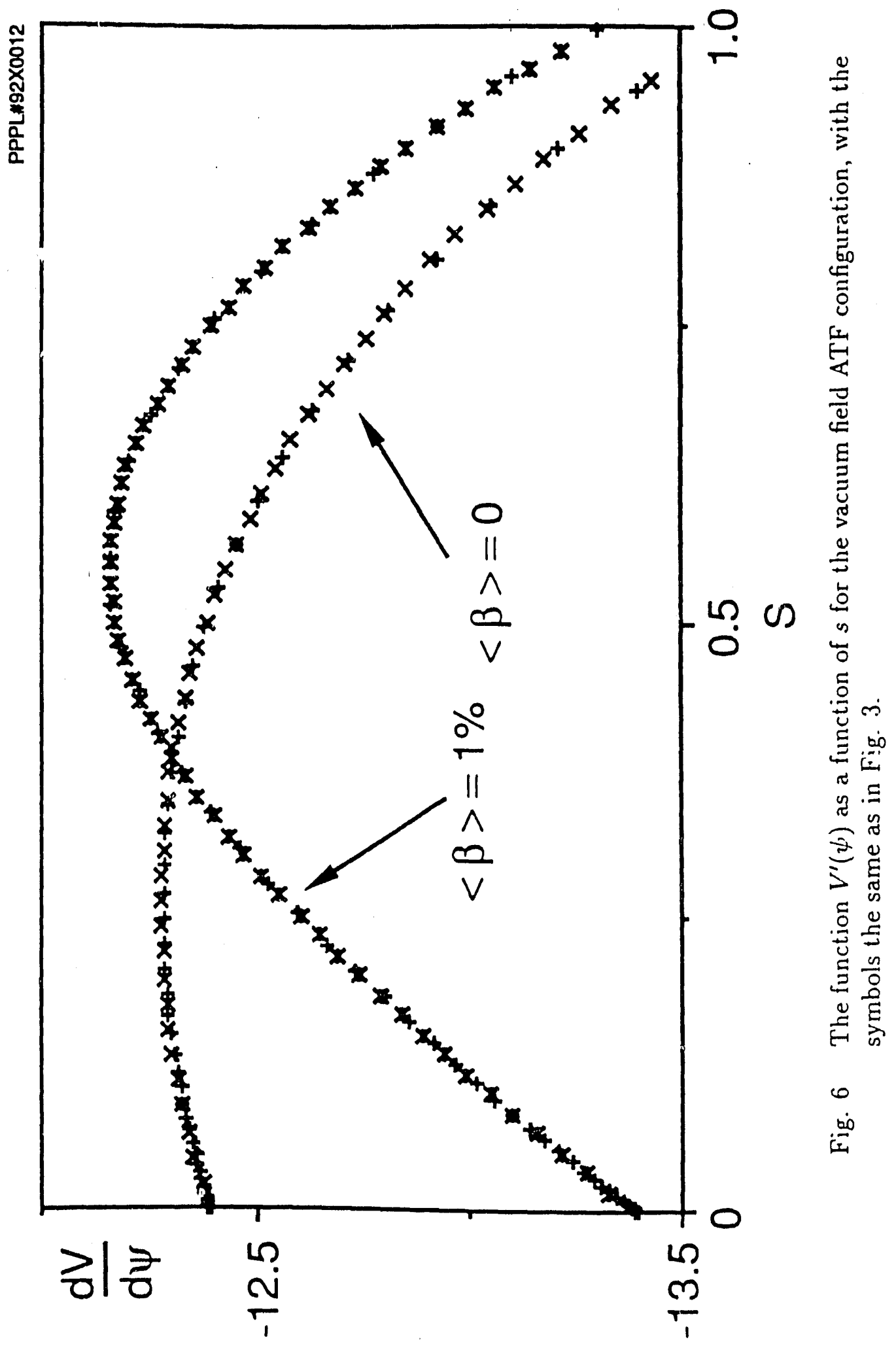




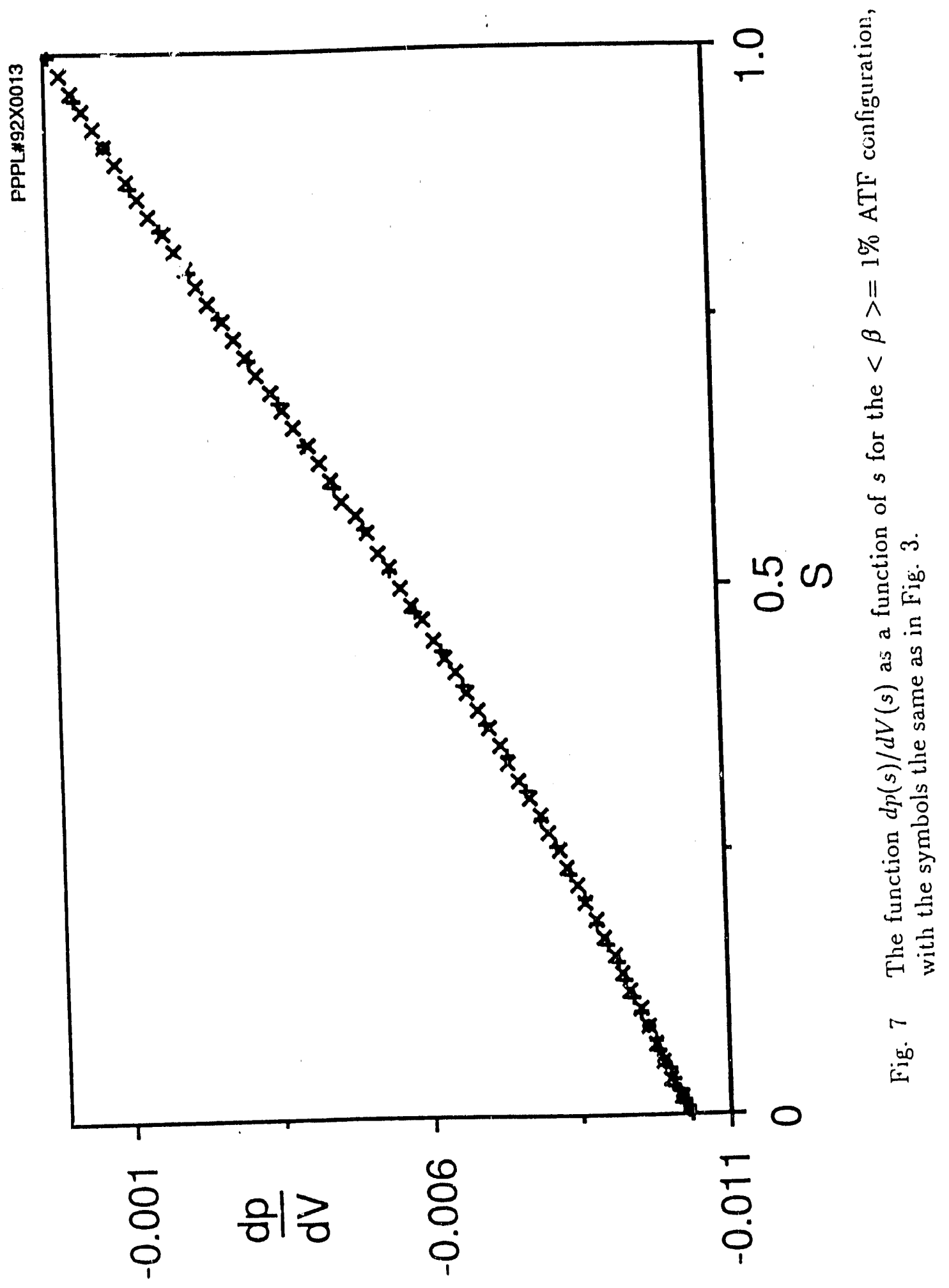




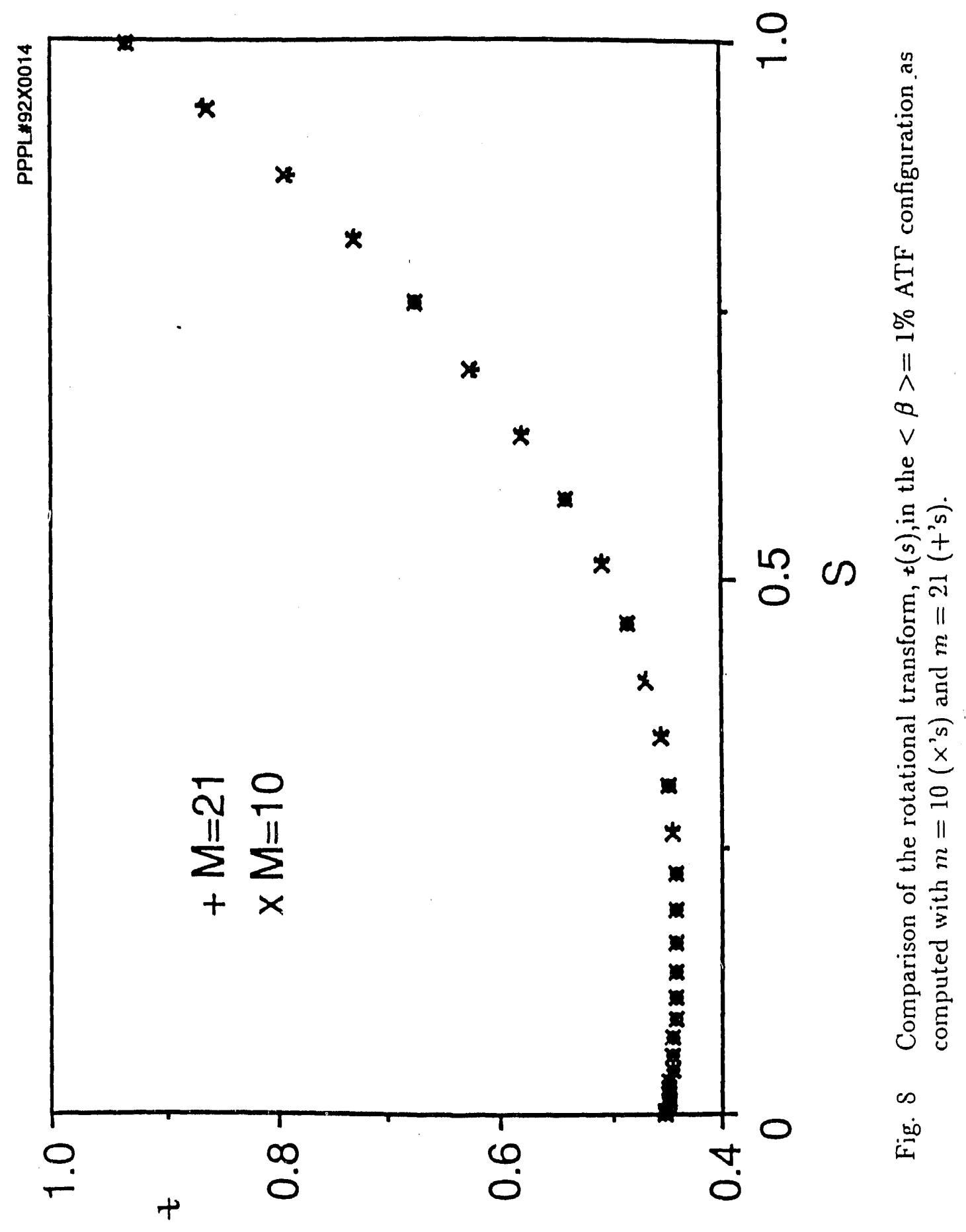




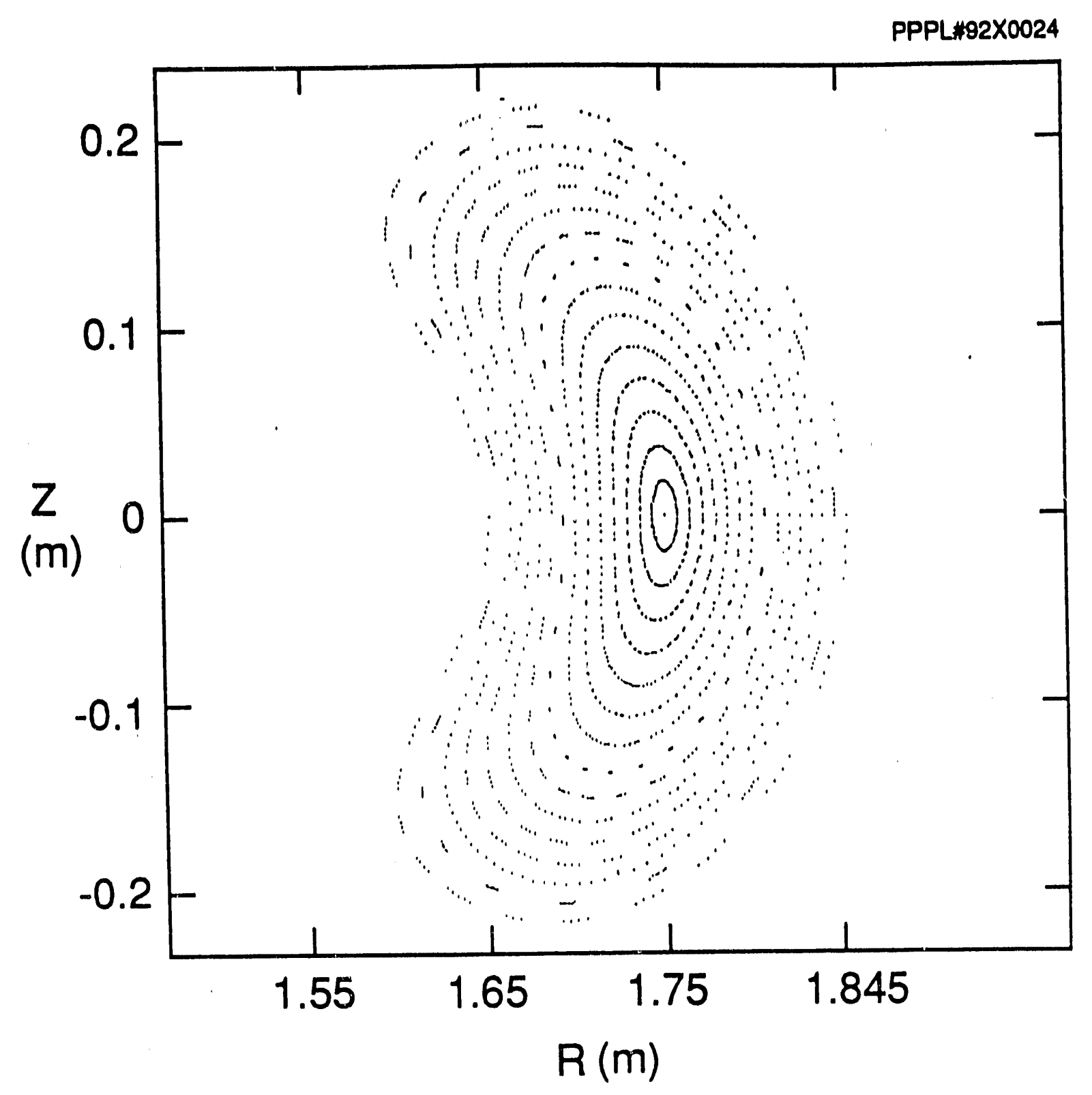

F1g. 9A 


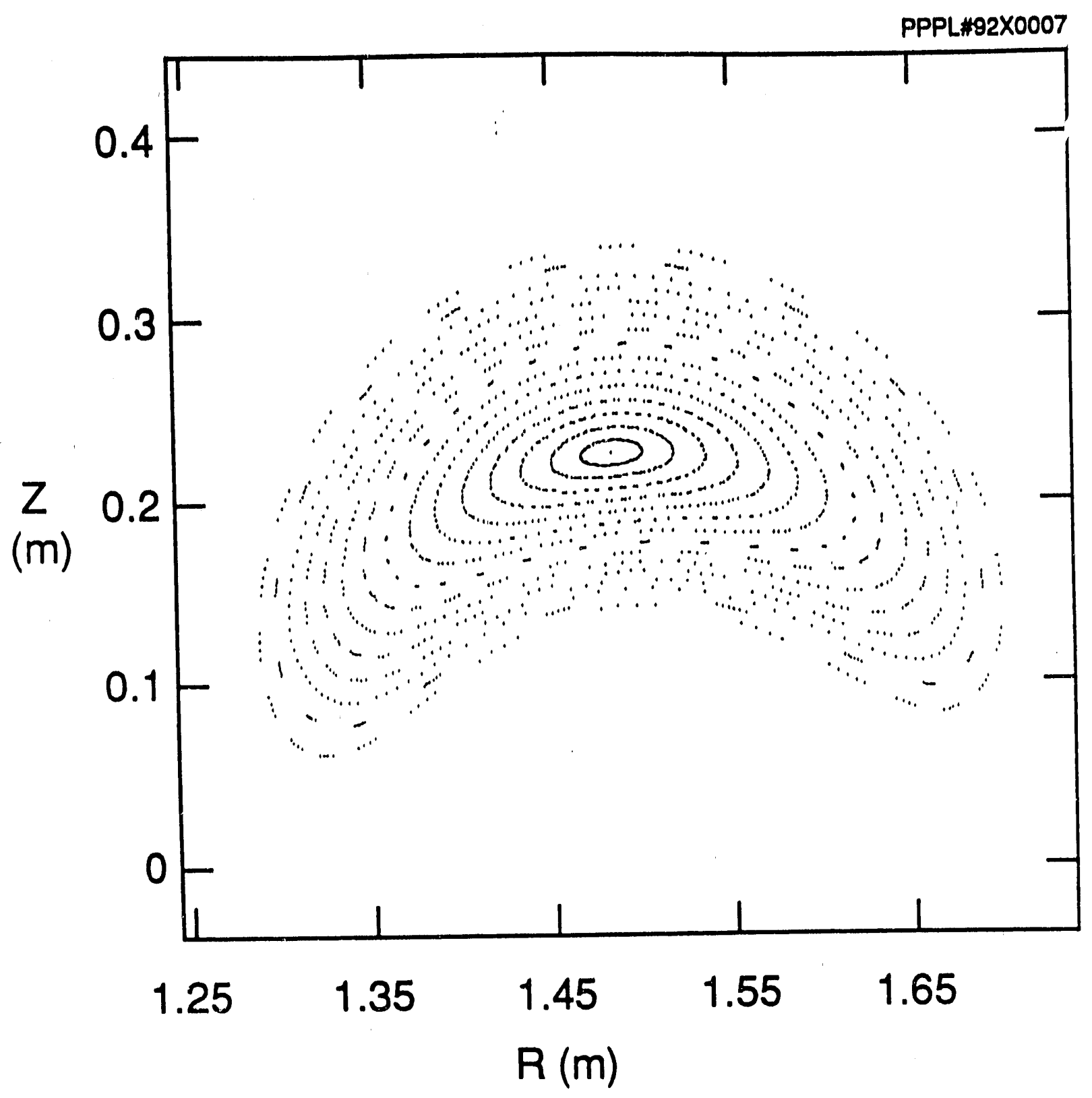

Fig. 9B 


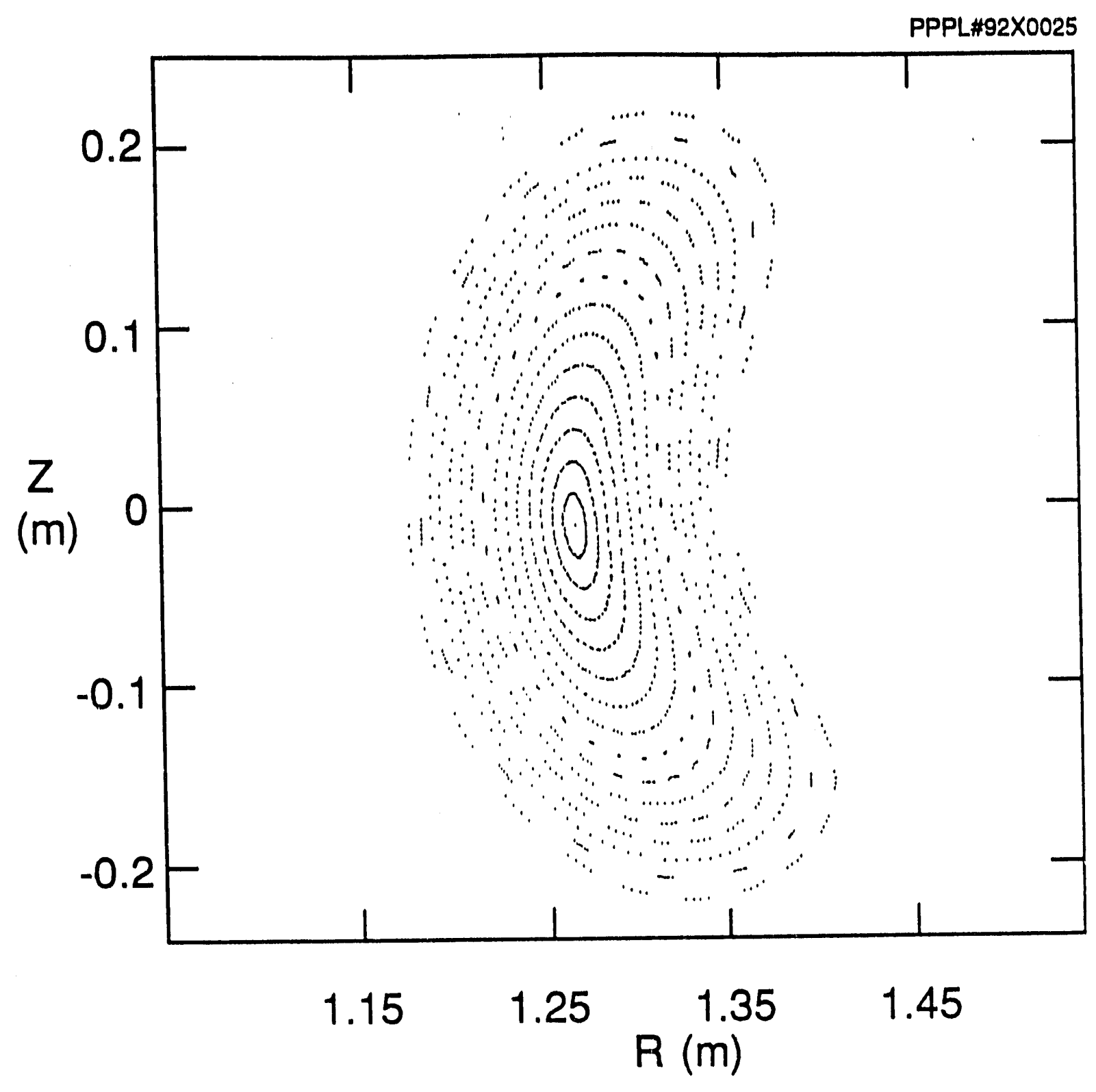

Fig. 9C 


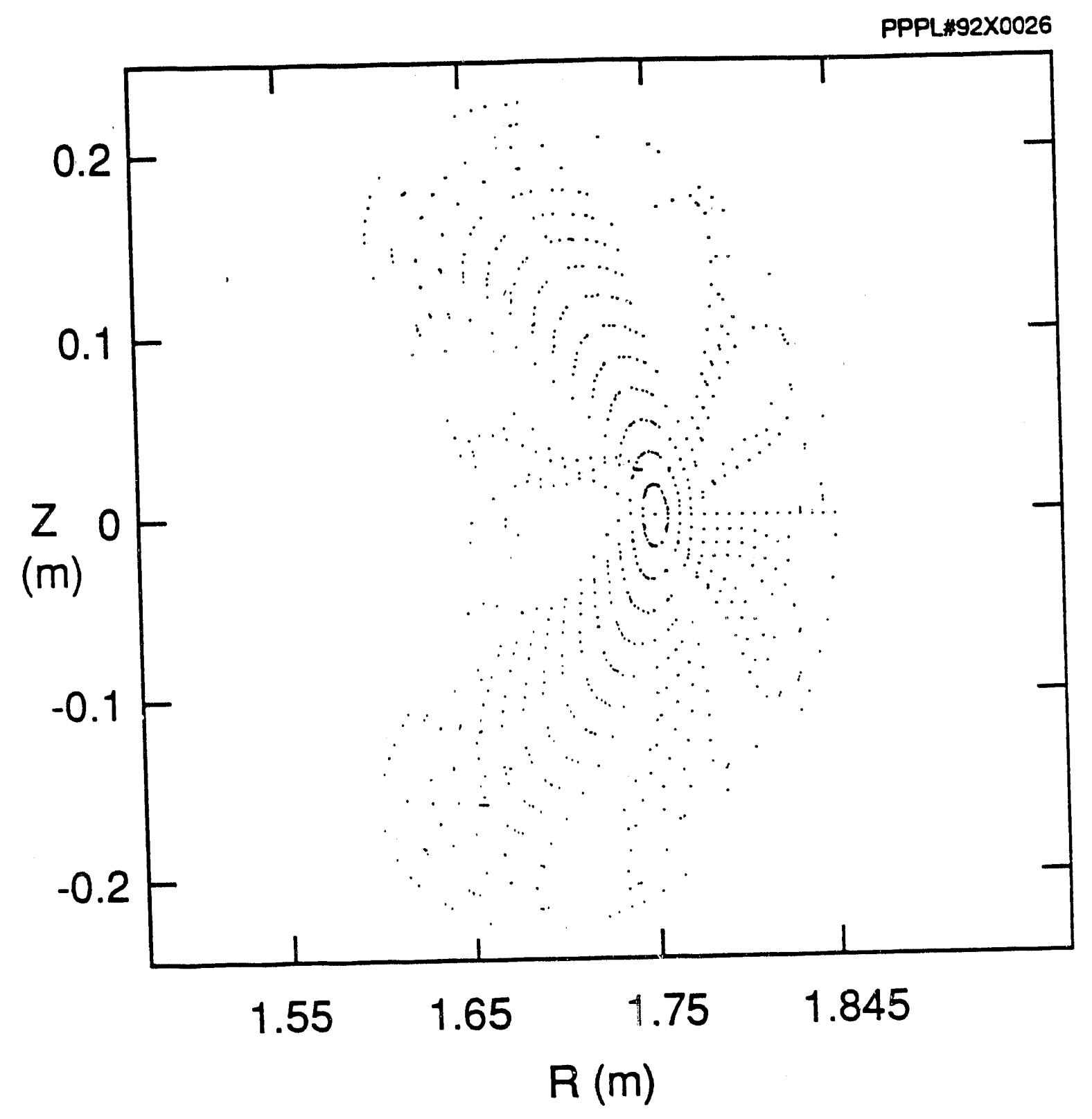

Fig. $10 \mathrm{~A}$ 


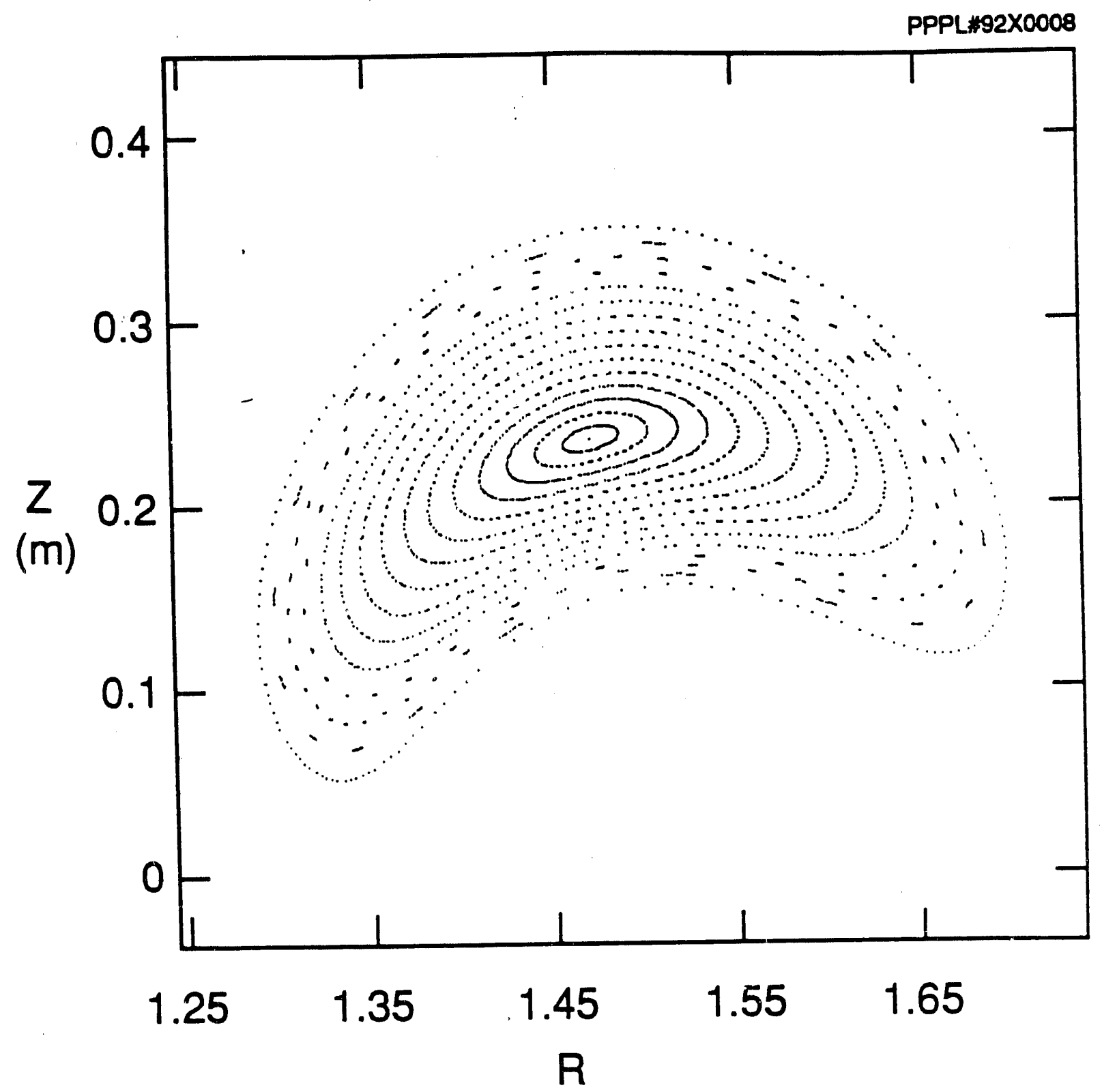

Fig. 1OB 


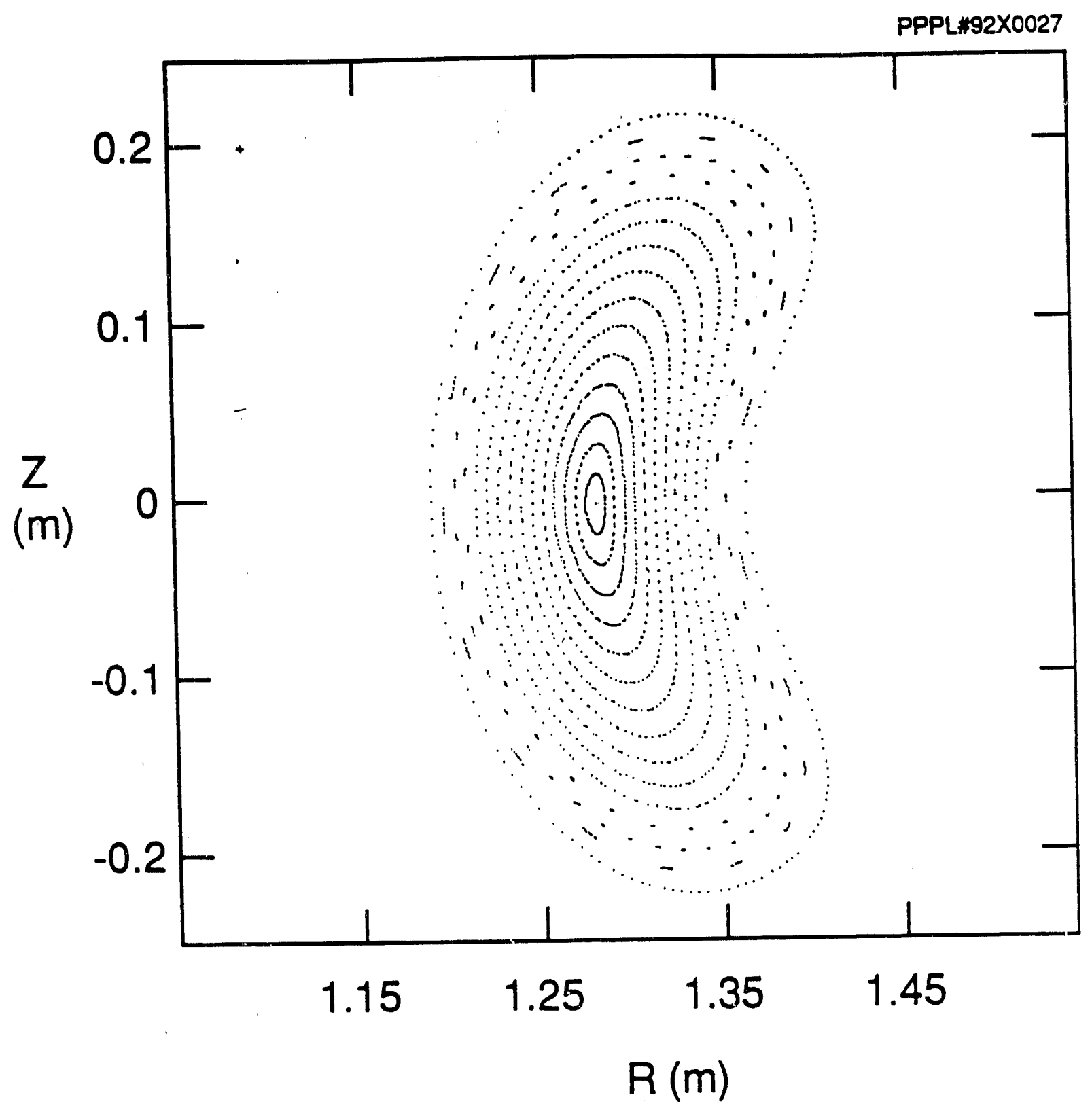

Fig. $10 \mathrm{C}$ 


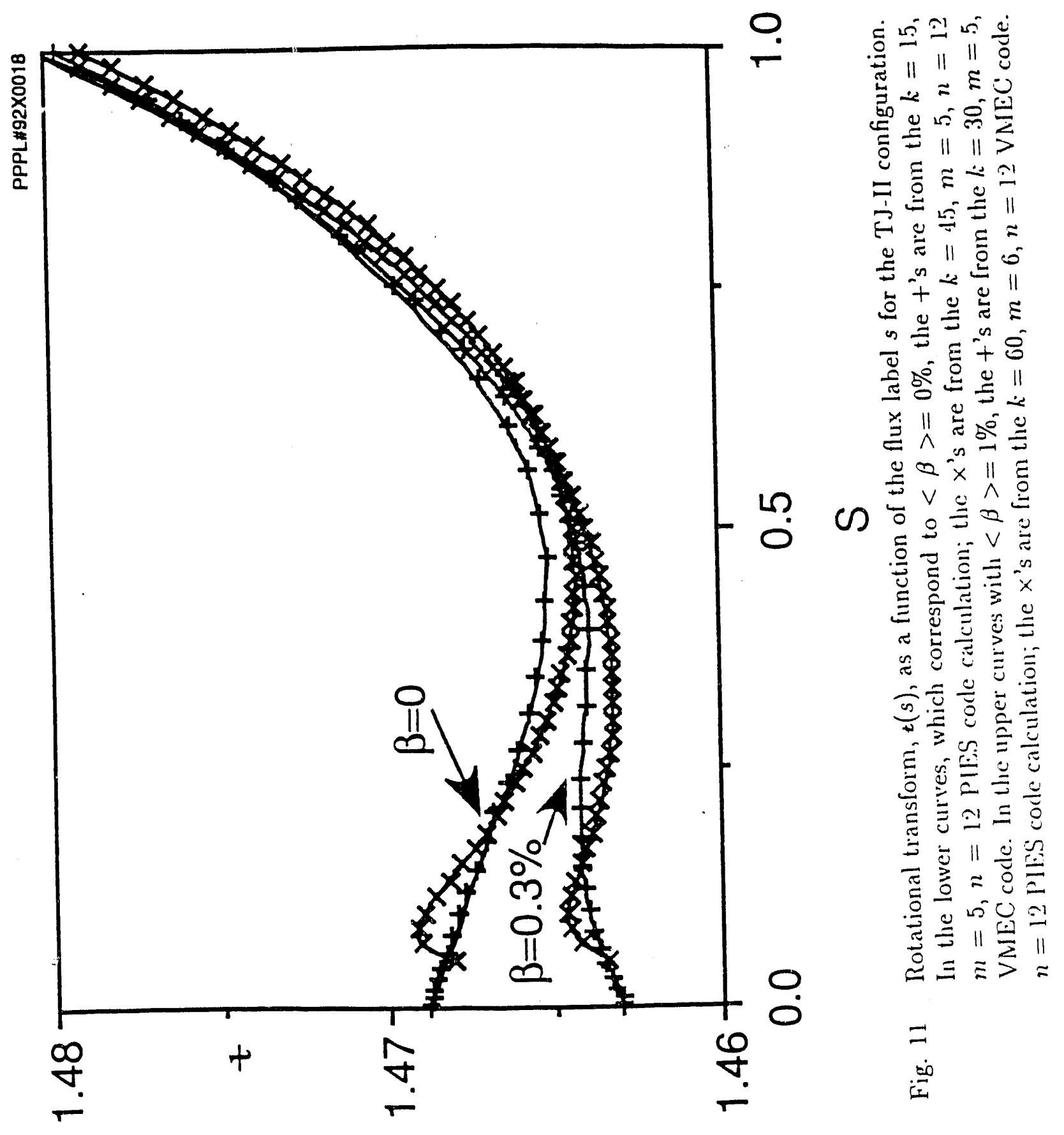




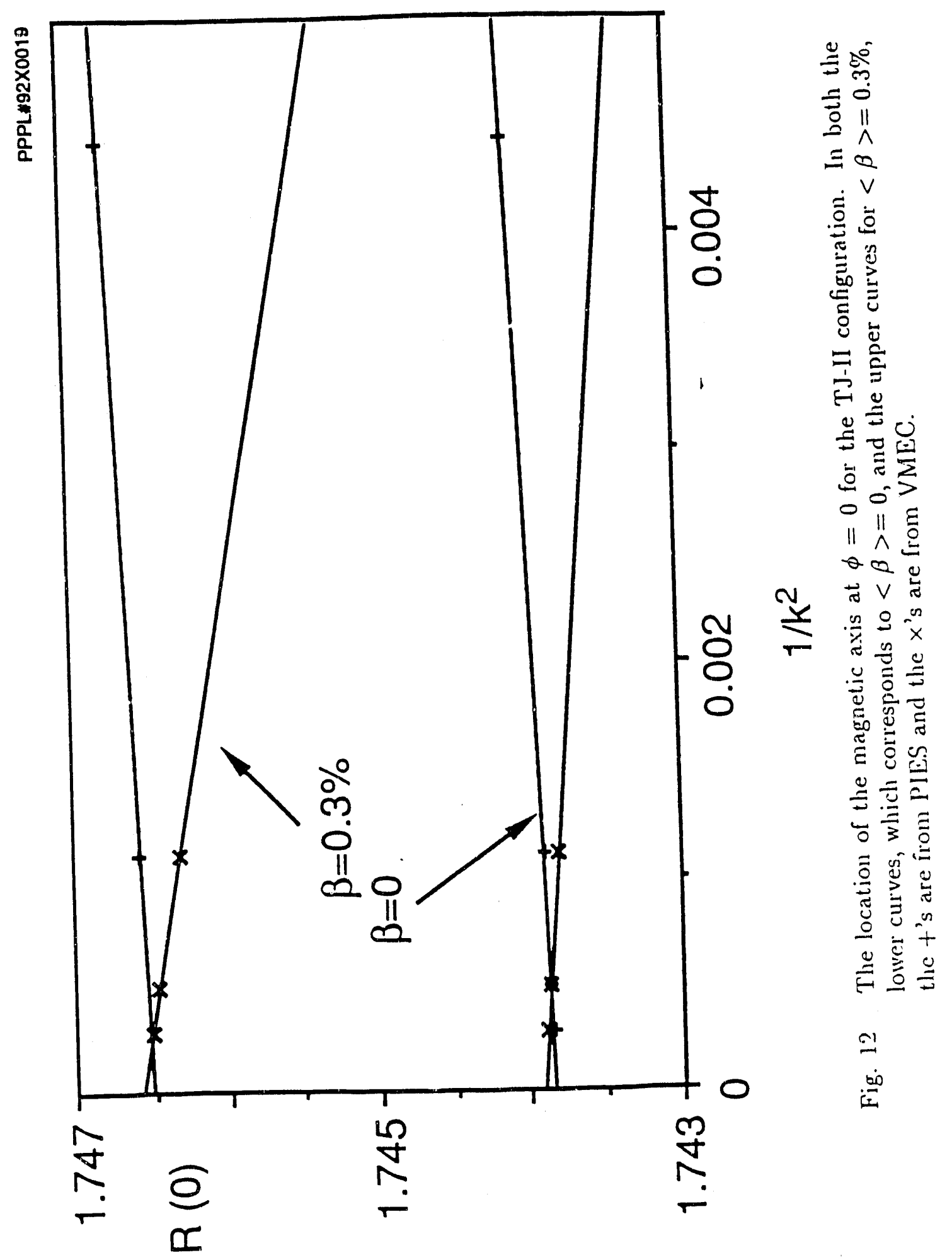




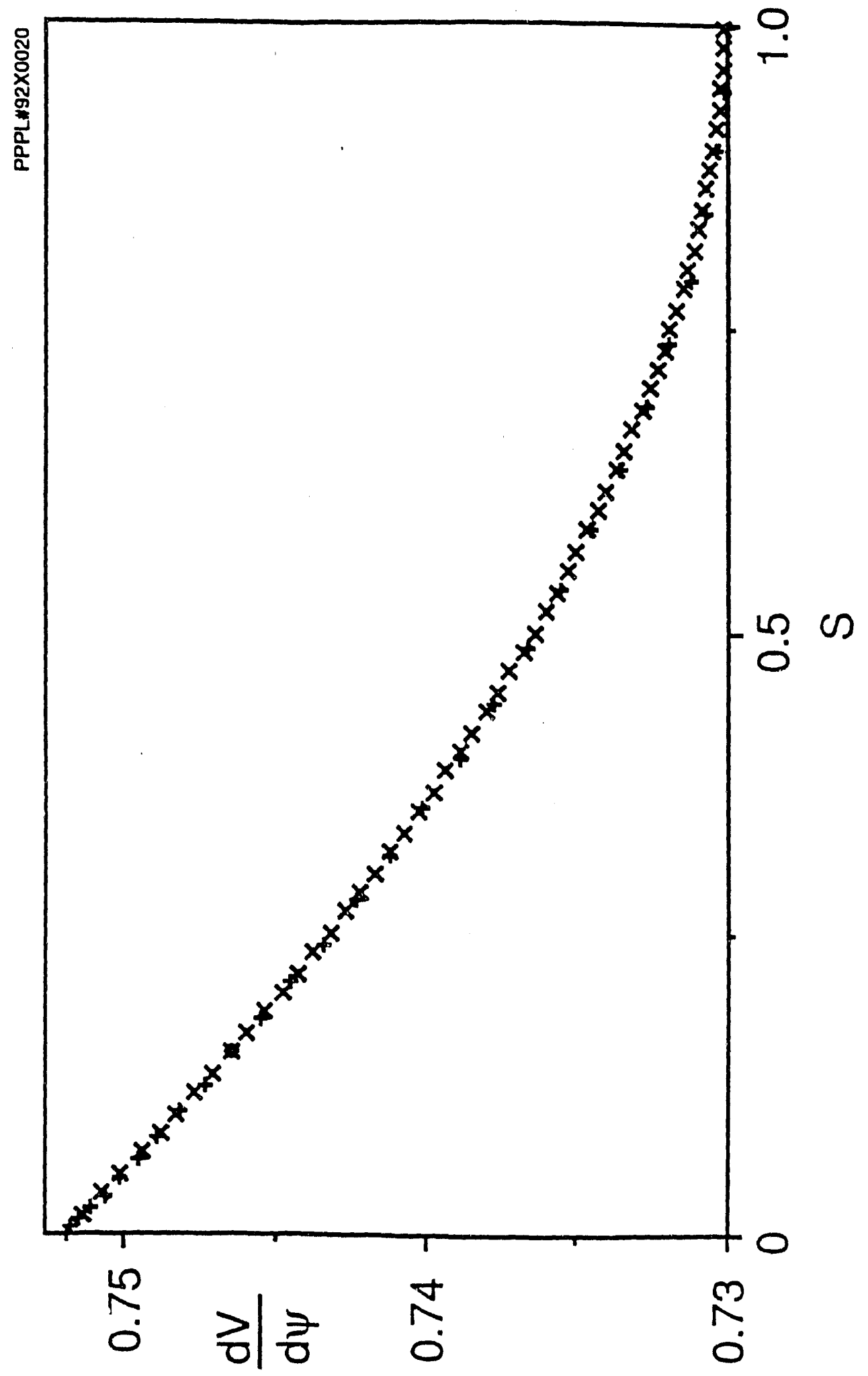

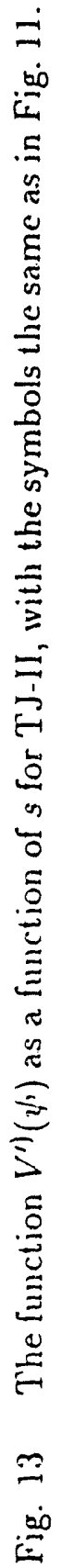


Dr. F. Peotoni, Univ. of Wollongong, AUSTRALUA

Prot. M.H. Brennen, Univ. of Sydnoy, AUSTRALLA

Pleema Rosearach Leb., Austratien NaL Univ., AUSTruLLA

Prof. I.R. Jomes, Findors Univ, AUSTRALLA

Prof. F. Cop, Inat for Theoredical Phycica, AUSTRIA

Prot. M. Hainciver, fratut for Theorotische Phyaik, AUSTRLA

Prot. M. Gooseens, Aetronomisch InstivU, BELGIUM

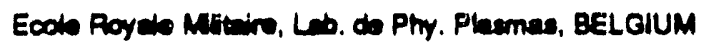

Commiscion-Europan, DQ. XII-Fusion Proo., BELGIUM

Prof. R. Bouciaus, Rajkeuniverditin Gent, BELCIUM

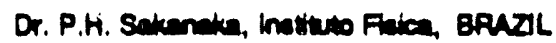

instivio Neciond Do Prequites Espadele-INPE, BRUZIL

Documents Orion, Abonic Energy of Cenada LId, CAMADA

Dr. M.P. Bechynatd, MPB Technologios, Inc., CANADA

Dr. H.M. Skeragend, Univ. of Sagkatchemen, CANAOA

Prof. J. Teichmam, Uriv. of Montred, CANAOA

Prot. S.A. Sromivean, Univ. of Cugory, CANADA

Prot. T.W. Johnaton, INRSEnorgin, CANAOA

Or. R. Botion, Contre canedien de husion magnotiqus, CANADA

Dr. C.R. Jemon. Univ. of Aborta, CANADA

Dr. P. Lukte, Komensto Univeradia, CZECHOSLOVAKIA

The Librarien, Cuhnem Leborationy, ENGLANO

Library, A61, Ruthartord Applwon Leboretory, ENGLAND

Mrs. S.A. Hutchincen, JET Lborery, ENGLAND

Dr. S.C. Sheme, Univ. of South Pacific, FWI ISLANDS

P. Menonen, Univ. of Heleinted, FINLAND

Prot. M.N. Buasece, Ecols Potymachriqus., FRANCE

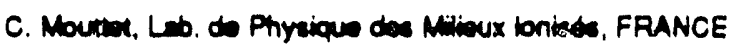

J. Radat, CENCADARACHE - Bat 506, FRANCE

Prof. E. Economou, Univ. of Cran, GREECE

Ma. C. Finnd, Univ. of lomina, GREECE

Dr. T. Mud, Academy Bibliographic Ser., HONG KONG

Proprint Librery, Hungerien Acactermy of Sa., HUNGARY

Dr. B. Descupta, Saha inat of Nucber Ptrycica, INDIA

Dr. P. Kaw, Inet. for Plaema Rosearch, INDLA

Dr. P. Rocenew, lered inst of Tectinobogy, ISPAEL

Librerien, Intemational Conter for Theo Phycics, ITALY

Miss C. Do Palo, Ascodiazione EURATOMAENEA, ITALY

Dr. G. Groses, latuto d Fisica del Plasma, ITALY

Prof. G. Rostengni, latitos Ges lenizzen DN Cnr, ITALY

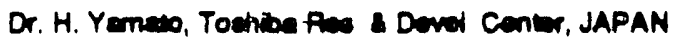

Prol. I. Kawckeni, Hiroghime Univ., JAPAN

Prof. K. Nlahilemwe, Hiroshima Univ., JAPAN

Director, Jepen Atomic Eneroy Rosearch Inst, JAPAN

Prot. S. Iroh, Kyuatu Univ., LAPAN

Rasearch Into. Cr., Nationa Instil for Fusion Scienco, JAPAN

Prol. S. Teneke, Kyow Univ., JAPAN

Librery, Kyoto Univ., JAPAN

Prot. N. Inowe, Univ, of Tokyo, LAPAN

Secretary, Pleama Section. Electroluchnical Lah. JAPAN

S. Morl, Techniced Antwor, LAEPM, JAPAN

Dr. O. Merd, Kumemow hat of Technology, JAPAN

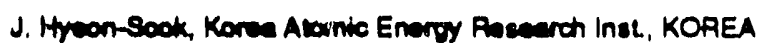

D.I. Chad, The Korea Adv. Inse of Sad a Tech., KOREA

Prot. B.S. Liby, Univ. of Wrikato, NEW ZEALAND

Inat of Phyeice, Chinan Aad SOI PEOPLE'S REP. OF CHINA

Librory, Inet of Plaeme Physica, PEOPLE'S REP. OF CHINA

Tainghu Uniw. Ubrary, PEOPLE'S REPUBUC OF CHINA

Z.J. S.W. Ina Phyuica, PEOPLE'S REPUBUC OF CHINA

Prot. J.A.C. Cubred, Instutus Superior Tecnico, PORTUGAL

Dr. O. Porrus, AL I CUZA Univ., ROMUNIA

Dr. J. do Viliers, Fusion Studios, AEC, S. AFRICA

Prot. M.A. Hewberg, Univ, of Nata, S. AfaICA

Prof. D.E. Km, Poheng inst of Sa. I Tech., SO. KOAEA

Prot. C.I.E.M.A.T, Fuivon Diviaion Library, SPAIN

Dr. L SWmio, Univ. OI UMEA, SWEDEN

Librery, Roy inct of Tectnology, SWEDEN

Prot. H. Wincimeon, Cheimers Univ. of Tech, SWEDEN

Contre Phys. Dese Plasernad, Ecolo Polytech, SWITERLAND

Bibliothen, Inat. Voor Plasma-Fysica, THE NETHERLANDS

Asse Prot. Dr. S. Cetir, Middo East Tech. Univ., TURKEY

Or. V.A. Gukhikh, Sai. Rase. Inat. Elactrophys.I Apperarus, USSR

Or. O.D. Ayutor, Siberian Branch of Academy of Sa., USSR

Dr. GA. Eisery, I.V. Kurchator Inat, USSR

Librevien, The Ukr.SSR Academy of Scionces, USSR

Dr. LM Kowizhmykh, Inat. of Generd Phyaica, USSR

Kemtorachungsaniege GmbH, Zentrabibtiothet. W. GERMANY

Bibliodnatk, inst FOr Plasmatorschung, W. GERMANY

Prot. K. Sctinder, Ruhr-Univernitu Bachum, W. GERMANY

Dr. F. Weoner, (ASOEX), Max Plenck-Inetitut, W. GERMANY

Librerien, Max-Plenck-Inatier, W. GEAMUNY

Prot. R.K Jenev, Inat of Physics, YUGOSLAVIA 

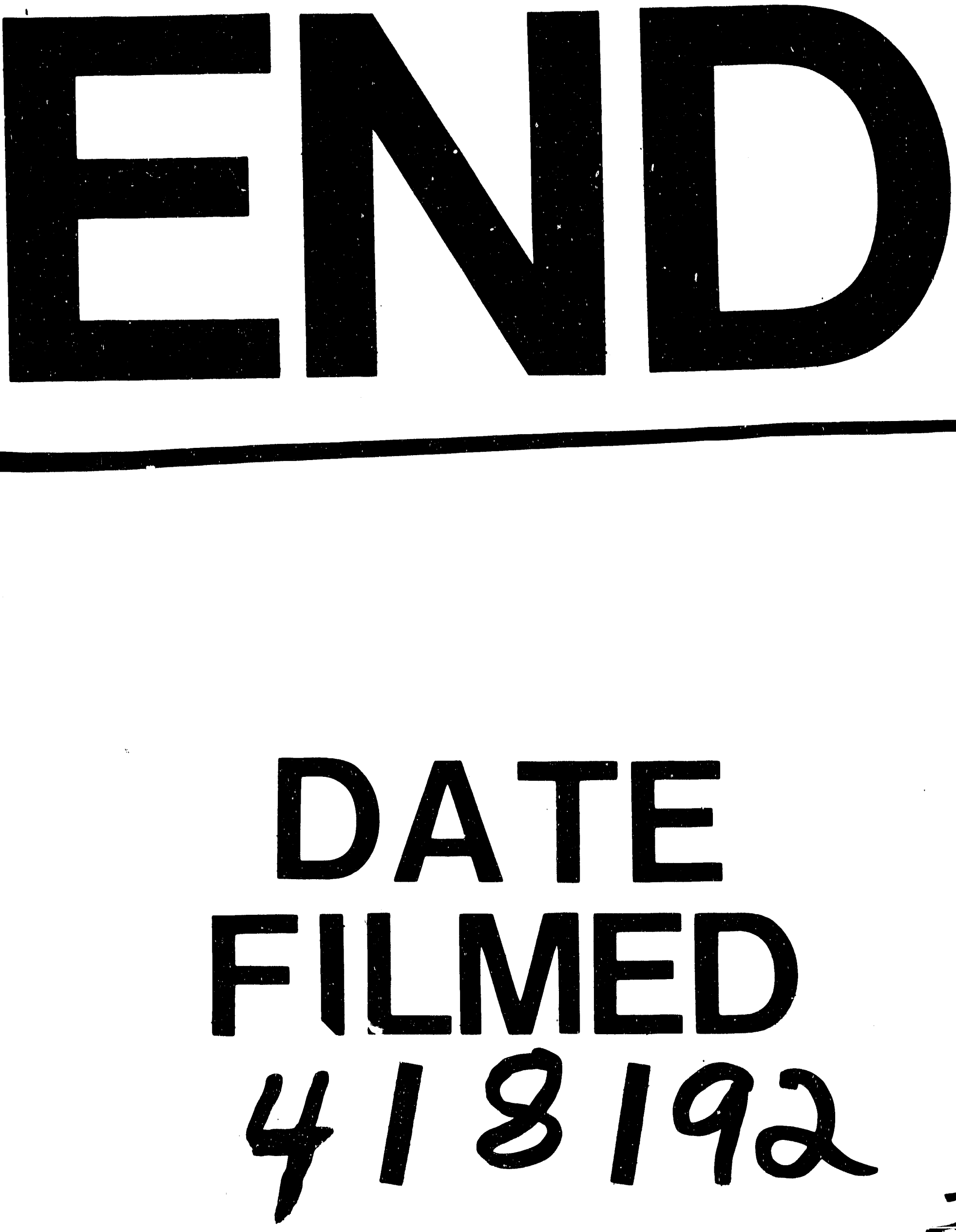

$I$ 
